\title{
Selection of IgG variants with increased FcRn binding using random and directed mutagenesis: impact on effector functions
}

\author{
Céline Monnet ${ }^{1}{ }^{*}$, Sylvie Jorieux ${ }^{1}$, Rémi Urbain ${ }^{2}$, Nathalie Fournier ${ }^{1}$, Khalil Bouayadi ${ }^{3}$, \\ Christophe De Romeuf ${ }^{1}$, Christian K. Behrens ${ }^{2}$, Alexandre Fontayne ${ }^{1}$ and Philippe Mondon ${ }^{1}$ \\ 1 LFB Biotechnologies, Lille, France \\ ${ }^{2}$ LFB Biotechnologies, Courtaboeuf, France \\ ${ }^{3}$ MilleGen, Labège, France
}

\section{Edited by:}

Jan Terje Andersen, Oslo University

Hospital, Norway

Reviewed by:

Scott D. Gray-Owen, University of Toronto, Canada

Marek Malecki, Phoenix Biomolecular

Engineering Foundation, USA

*Correspondence:

Céline Monnet, LFB Biotechnologies,

59 Rue de Trévise, BP2006, Lille

Cedex 59011, France

e-mail:monnetc@lfb.fr
Despite the reasonably long half-life of immunoglogulin $\mathrm{G}(\mathrm{lgGs})$, market pressure for higher patient convenience while conserving efficacy continues to drive IgG half-life improvement. IgG half-life is dependent on the neonatal $F_{c}$ receptor ( $\left.F_{C} R n\right)$, which among other functions, protects IgG from catabolism. FcRn binds the $F_{c}$ domain of $\lg G$ at an acidic $\mathrm{pH}$ ensuring that endocytosed IgG will not be degraded in lysosomal compartments and will then be released into the bloodstream. Consistent with this mechanism of action, several Fc-engineered IgG with increased FcRn affinity and conserved $\mathrm{pH}$ dependency were designed and resulted in longer half-life in vivo in human FcRn-transgenic mice (hFcRn), cynomolgus monkeys, and recently in healthy humans. These IgG variants were usually obtained by in silico approaches or directed mutagenesis in the FcRn-binding site. Using random mutagenesis, combined with a $\mathrm{pH}$-dependent phage display selection process, we isolated IgG variants with improved FcRn-binding, which exhibited longer in vivo half-life in $\mathrm{hFcRn}$ mice. Interestingly, many mutations enhancing Fc/FcRn interaction were located at a distance from the FcRn-binding site validating our random molecular approach. Directed mutagenesis was then applied to generate new variants to further characterize our lgG variants and the effect of the mutations selected. Since these mutations are distributed over the whole Fc sequence, binding to other Fc effectors, such as complement C1q and Fc $\gamma R$, was dramatically modified, even by mutations distant from these effectors' binding sites. Hence, we obtained numerous IgG variants with increased FcRn-binding and different binding patterns to other Fc effectors, including variants without any effector function, providing distinct "fit-for-purpose" Fc molecules. We therefore provide evidence that half-life and effector functions should be optimized simultaneously as mutations can have unexpected effects on all Fc receptors that are critical for IgG therapeutic efficacy.

Keywords: complement C1q, directed mutagenesis, Fc engineering, Fc gamma receptors, FcRn, IgG, random mutagenesis, therapeutic mAbs

\section{INTRODUCTION}

Therapeutic monoclonal antibodies (mAbs) have proven successful in the clinic and are now in widespread use for the treatment of a variety of diseases including cancer, autoimmune, and infectious diseases. At the moment, new therapeutic mAbs are undergoing clinical trials at a record pace constantly filling very dynamic business pipelines (1). Most therapeutic mAbs are human or humanized molecules of the immunoglogulin $\mathrm{G}$ isotype $(\operatorname{IgG})$, specifically IgG1, IgG2, and IgG4, which bind with high affinity the human neonatal $\mathrm{Fc}$ receptor $(\mathrm{FcRn})$, in a strictly $\mathrm{pH}$-dependent

Abbreviations: ADCC, antibody-dependent cell-mediated cytotoxicity; ADCP, antibody-dependent cell-mediated phagocytosis; CDC, complement-dependent cytotoxicity; Fc $\gamma \mathrm{R}$, Fc gamma receptor; FcRn, neonatal Fc receptor; IgG, immunoglobulin of the G isotype; $\mathrm{mAb}$, monoclonal antibody; NK, natural killer; PK, pharmacokinetics; SPR, surface plasmon resonance; WT, wild-type. manner. This $\mathrm{Fc} / \mathrm{FcRn}$ binding is largely responsible for the long half-life of IgGs as FcRn prevents IgG intracellular degradation. Following pinocytosis, IgGs are internalized into the endosomes of cells where the low $\mathrm{pH}$ ( $\mathrm{pH} 5-6)$ promotes binding to FcRn with nanomolar affinity. Bound IgG-Fc/FcRn complexes are recycled back to the cell surface and dissociate at the neutral $\mathrm{pH}$ of the extracellular fluid, returning thus to the blood circulation. Due to the same mechanism, FcRn is also involved in IgG transport across placental, fetomaternal, and polarized cellular barriers (2, 3 ). This property has been successfully exploited for pulmonary delivery and intranasal immunization with Fc-fusion proteins (4, 5). Recently, FcRn was shown to enable transepithelial transport of Fc-targeted nanoparticles delivered orally in mice. This innovative study paves the way for potential oral administration to treat chronic diseases (6). FcRn properties in transport and catabolism mainly occur in endothelial and epithelial cells. In human, FcRn 
is also expressed by many immune cells such as macrophages, monocytes, and dendritic cells. Several recent studies demonstrated unexpected roles for FcRn in antigen presentation (7-9) and phagocytosis (10) revealing a wide range of functions for this receptor in immunological and non-immunological mechanisms. A fundamental understanding of FcRn's versatile roles will be essential to guide the development of therapeutic mAbs- and Fc-fusion proteins (11), especially when engineering Fc variants with modulated FcRn binding (12).

Given the considerable role of FcRn in antibody homeostasis, the IgG-Fc/FcRn interaction has been extensively studied for the last 20 years by directed mutagenesis (13) and crystallography (14). The FcRn-binding site is structurally conserved among species and is localized in the $\mathrm{CH} 2 / \mathrm{CH} 3$ interdomain Fc region. Based on this knowledge, Fc-engineered mAbs with increased FcRn affinity and conserved $\mathrm{pH}$ dependency were obtained by alanine scanning (13), directed mutagenesis (15), and in silico approach (16-18) focused on the FcRn-binding site. The resulting Fc variants usually include two to three substitutions in or close to the FcRn-binding site. Consistent with FcRn's role in IgG catabolism, such engineered mAbs showed longer half-life in vivo in human FcRn-transgenic mice (hFcRn mice) and/or cynomolgus monkeys (16-24). For instance, Fc variants of the anti-VEGF bevacizumab and the antiEGFR cetuximab (Fc-LS, M428L/N434S) demonstrated half-lives extended up to almost fivefold in hFcRn mice and threefold in cynomolgus monkeys (18). When introduced in a CTLA4-Fcfusion protein, this Fc-LS variant exhibited increased half-life in cynomolgus monkeys as well, albeit at a lower level than for mAbs (1.4-fold increase) (25). Remarkably, for the first time in healthy humans an Fc-engineered anti-RSV mAb (motavizumab-YTE, M252Y/S254T/T256E) showed a significant serum half-life extension (up to 100 days, two- to fourfold increase), fully confirming in humans the results previously obtained in animal models (19, 26). This proof of concept validated for the first time in humans the usefulness of increasing FcRn binding to obtain mAbs with extended half-life. Such improved therapeutic mAbs should prove attractive for developers as they offer several advantages allowing a positive differentiation from the competition. First, treatment intervals could be increased while keeping the same dosing, resulting in better patient convenience and reduced costs. Second, for the same efficacy, with the same dosing interval, drug quantities may be lowered, reducing costs as well. Finally, the use of the same dose and dosing interval as the parent antibody should result in higher drug exposure. Interestingly, when this setting was used, greater anti-tumor activity was observed for the Fc-LS variants tested in hFcRn/Rag1-/- tumor xenografted mice, showing a positive correlation between FcRn-binding enhancement and in vivo efficacy (18). Whether this improved therapeutic efficacy is solely due to prolonged drug exposure, or also due to other FcRn-mediated mechanisms, needs to be elucidated.

On the other hand, it is now clearly established that the therapeutic efficacy of mAbs substantially rely on their ability to engage the immune system via their Fc domain (27). This Fc-dependent engagement is mainly mediated by crosslinking of Fc $\gamma$ receptors ( $F c \gamma R s)$ widely expressed on many innate immune effector cells such as NK cells, monocytes, macrophages, and neutrophils. Immune effector cells express one or more activating Fc $\gamma$ Rs, Fc $\gamma$ RI
(CD64), Fc $\gamma$ RIIA (CD32a), and Fc $\gamma$ RIIIA (CD16a), and/or the only inhibitory receptor Fc $\gamma$ RIIB (CD32b). Following engagement of their activating Fc $\gamma$ Rs, these cells kill tumor or infected cells through antibody-dependent cellular cytotoxicity (ADCC) or phagocytosis (ADCP). Natural polymorphisms of these Fc $\gamma$ Rs have been described in humans, resulting in modulated affinities for IgG subclasses. These Fc $\gamma$ Rs polymorphisms, especially the Fc $\gamma$ RIIIA polymorphism (V/F158), influence patients' response to treatment with therapeutic mAbs (28). More favorable clinical responses were indeed observed in patients homozygous for the higher-affinity allele of Fc $\gamma$ RIIIA (V158) in various disorders: with the anti-CD20 rituximab in non-Hodgkin lymphomas (29), in immune thrombocytopenia (30), and in rheumatoid arthritis (31), with the anti-HER2 trastuzumab in metastatic breast cancer (32), with the anti-EGFR cetuximab in metastatic colorectal cancer (33), and with the anti-TNF $\alpha$ infliximab in Crohn's disease (34). These findings suggest a crucial role for Fc $\gamma$ RIIIA in the in vivo activity of therapeutic mAbs because the V158 polymorphic variant displays a higher affinity for IgG1 and increased ADCC. Therefore, in order to enhance therapeutic activity, many protein-Fc-engineered mAbs with increased Fc $\gamma$ RIIIA binding were designed (35) using alanine scanning $(13,36)$, random mutagenesis (37), and in silico approach (38). Glyco-engineering was also successfully used to that aim, as Fc glycan content strongly influences $\mathrm{Fc} / \mathrm{Fc} \gamma \mathrm{RIIIA}$ interaction, contrarily to the $\mathrm{Fc} / \mathrm{FcRn}$ interaction, which is not dependent on the glycan structure. The absence of fucose residues on the Fc glycan moiety of mAbs has long been associated with increased affinity for Fc $\gamma$ RIIIA (39). Afucosylated or low fucosylated mAbs with strongly enhanced cytotoxicity were obtained by cellular engineering. More than 20 glyco-engineered mAbs, with higher ADCC, are now in clinical studies and two have already been approved since 2012 (mogamulizumab and obinutuzumab) confirming the success of this approach (40).

In a previous study, we demonstrated that glyco-engineering to improve cytotoxicity and protein-Fc engineering to increase half-life can be combined to further optimize therapeutic mAbs (41). In our approach, we used a random mutagenesis technology with a $\mathrm{pH}$-dependent phage display selection process to isolate several Fc variants of human IgG1 with improved FcRn affinity. Interestingly, some of the identified mutations, enhancing Fc/FcRn interaction, were located at a distance from the FcRn-binding site validating our random molecular approach. When produced as low fucosylated molecules (EMABling ${ }^{\circledR}$ platform), our IgG variants demonstrated increased serum persistence in hFcRn mice (half-life of $23 \mathrm{~h}$ for the IgG-WT and $64 \mathrm{~h}$ for our best IgG variant) as well as conserved enhanced ADCC for five out of our six best variants. In this study, we used directed mutagenesis to further characterize the effect of the mutations previously selected on the $\mathrm{Fc} / \mathrm{FcRn}$ interaction. Because these mutations are distributed on the whole Fc sequence, we assessed the binding of several Fc variants to the complement $\mathrm{Clq}$ and $\mathrm{Fc} \gamma \mathrm{Rs}$, and evaluated effectors functions, ADCC and CDC, as well. We therefore obtained numerous IgG variants with increased FcRn binding and different binding patterns to other $\mathrm{Fc}$ receptors and $\mathrm{Clq}$, including variants without any effector function, providing distinct "fit-for-purpose" Fc molecules. 


\section{MATERIALS AND METHODS EXPRESSION AND PURIFICATION OF HUMAN FCRn}

Soluble human FcRn was produced by GTP Technology using the baculovirus expression system as previously described (42). The $\alpha$-chain cDNA encoding the leader peptide and extracellular domains (codons 1-290) was tagged with a TEV sequence and a $6 \times$ polyhistidine tag. The derivative $\alpha$-chain and the $\beta 2$ microglobulin chain were cloned into $\mathrm{pFastBacDual}$ under the P10 and polyhedrine promoters, respectively. A fusion protein containing the $\beta 2$-microglobulin chain and the $\alpha$-chain fused to the amino terminal part of the bacteriophage $\mathrm{p} 3$ protein and the CVDE protein (FcRn-p3) was also produced. Proteins with more than $90 \%$ purity were obtained after IgG-Sepharose and IMAC purification steps.

\section{PHAGE-ELISA ASSAYS OF Fc VARIANTS}

The human Fc gene encoding amino acid residues 226-447 [EU index as in Kabat (43) and Supplementary Material], derived from a human $\operatorname{IgG} 1$ heavy chain $(\mathrm{G} 1 \mathrm{~m} 1,17$ allotype), was cloned into the phagemid vector pMG58 (pMG58-Fc226) as a BamHI/EcoRI fragment using standard PCR protocols. Wild-type $\mathrm{Fc}$ (Fc-WT) and variants were expressed on the surface of the bacteriophage M13 $(41,44)$ and their FcRn-binding characteristics were determined using an ELISA test at $\mathrm{pH}$ 6.0. Briefly, E. coli XL1-Blue bacteria containing the Fc variants (in pMG58 vector) were grown as separate clones on a 96-well plate in $800 \mu \mathrm{l}$ cultures in $2 \mathrm{YT}$ medium supplemented with $100 \mu \mathrm{g} / \mathrm{ml}$ ampicillin, $15 \mu \mathrm{g} / \mathrm{ml}$ tetracycline, and $1 \%(\mathrm{w} / \mathrm{v})$ glucose at $30^{\circ} \mathrm{C}$, $230 \mathrm{rpm}$ until $\mathrm{OD}_{600 \mathrm{~nm}}=0.6$ is reached. Cells were then infected with M13 helper phage (M13KO7, New England Biolabs, ratio bacteria/phage $=1 / 3$ ) at $37^{\circ} \mathrm{C}$ for $20 \mathrm{~min}$. Phage-Fc were produced overnight at $26^{\circ} \mathrm{C}, 230 \mathrm{rpm}$ in $2 \mathrm{YT} / \mathrm{ampicillin} /$ glucose with $0.5 \mathrm{mM}$ IPTG and $30 \mu \mathrm{g} / \mathrm{ml} \mathrm{kanamycin} \mathrm{and} \mathrm{recovered} \mathrm{in} \mathrm{the} \mathrm{super-}$ natants after centrifugation for $30 \mathrm{~min}$. at 3,000 $\times \mathrm{g}$. These supernatants were directly diluted (1/2 and $1 / 4)$ in phosphate buffer $\mathrm{pH}$ $6.0(100 \mathrm{mM}$ sodium phosphate, $50 \mathrm{mM}$ sodium chloride $\mathrm{pH} 6.0$, called P6), supplemented with $5 \%$ skimmed milk and $0.1 \%$ Tween20 , and tested on Maxisorp immunoplates previously coated with $0.25 \mu \mathrm{g} \mathrm{FcRn-p3/well} \mathrm{and} \mathrm{blocked} \mathrm{with} \mathrm{5 \%} \mathrm{skimmed} \mathrm{milk} \mathrm{in} \mathrm{P6.}$ After incubation for $2 \mathrm{~h}$ at $37^{\circ} \mathrm{C}$, wells were washed three times with P6/0.1\% Tween-20 and bound phages were detected with an HRP anti-M13 antibody (GE Healthcare).

\section{DIRECTED MUTAGENESIS}

Directed mutagenesis was performed to construct positive controls and remove or add point mutations by overlap PCR using standard protocols. All the variants were constructed with overlapping primers containing the desired mutations and the primers MG619 (5'-AGTACTGACTCTACCTAGGATCCTGCCCACCGTGC$\left.3^{\prime}\right)$ and MG-621 (5'-ACTGCTCGATGTCCGTACTATGCGGCCG CGAATTC-3') for cloning (BamHI and EcoRI restriction sites are underlined and italic characters correspond to non-specific tails). All the variants constructed by directed mutagenesis are described in patent applications WO2010106180 (45) and WO2012175751 (46). The positive controls for FcRn were the double variant $\mathrm{T} 250 \mathrm{Q} / \mathrm{M} 428 \mathrm{~L}(16,17)(\mathrm{Fc}-\mathrm{QL})$, the triple variant M252Y/S254T/T256E (15) (Fc-YTE), and the double variant M428L/N434S (Fc-LS) (18). The positive control for Fc $\gamma$ RIIIA was
S239D/I332E (C1) (38), for the complement C1q; K326W/E333S (C3) (47), for Fc $\gamma$ RIIA; G236A (C4) (48), and for Fc $\gamma$ RIIB; S267E/L328F (C5) (49).

\section{PRODUCTION OF IgG VARIANTS IN YB2/0 CELLS}

The Fc WT and variants were produced in IgG format with an anti-CD20 specificity based on the Fv domain of CAT 13.6E12 (50), using the YB2/0 cell line (ATCC, CRL-1662). Heavy and light chains of the anti-CD20 antibody were cloned into the CHK62208 vector, optimized for production in $\mathrm{Y} 2 \mathrm{~B} / 0$ cells, as previously described (41). Each linearized expression construct was introduced by electroporation into $5 \times 10^{6} \mathrm{YB} 2 / 0$ cells. Cells were then expanded to 25,000 cells $/ \mathrm{ml}$ in RPMI 1640 medium $+5 \% \mathrm{v} / \mathrm{v}$ dialyzed FCS (Invitrogen) and dispensed in $1 \mathrm{ml} /$ well into 24well plates. After 3 days, selection pressure was applied by adding geneticin (Invitrogen) and methotrexate (Sigma) to obtain final concentrations of $0.5 \mathrm{~g} / \mathrm{l}$ and $25 \mathrm{mM}$ respectively, in $2 \mathrm{ml} / \mathrm{well}$. After 11 days, resistant cells were pooled for each construct and progressively expanded with DMEM medium $+5 \% \mathrm{v} / \mathrm{v}$ Ultra-low IgG FCS (Invitrogen) until two 2 l-roller bottles, each containing 0.91 of cell suspension can be incubated at $2 \mathrm{rpm}$. Cells were allowed to grow and die (4-5 days) before supernatant collection, clarification by low-speed centrifugation and volume reduction by ultra-filtration using a Pellicon XL Filter (Millipore). The concentrated culture supernatants were injected into a HiTrap protein A FF column (GE Healthcare). Bound antibodies were eluted with $0.1 \mathrm{M}$ sodium citrate, $\mathrm{pH} 3.0$, and fractions were neutralized using $100 \mu \mathrm{l}$ of $1 \mathrm{M}$ Tris- $\mathrm{HCl} \mathrm{pH} 7.5 / \mathrm{ml}$ of elution buffer. Fractions containing the antibodies were pooled and dialyzed against PBS pH 6.0, and the samples were sterilefiltered $(0.22 \mu \mathrm{m})$ and stored at $4^{\circ} \mathrm{C}$. The purified IgGs were analyzed using SDS-PAGE under non-reducing and reducing conditions as well as analytical gel filtration (on Superdex 200 10/300 GL with an AKTA prime system, GE Healthcare) in order to estimate aggregate contents and potential contaminants. Coomassie Blue-stained gels indicated that the IgGs, whatever the mutations, had $>95 \%$ purity and displayed the characteristic heavy and light chain bands. Purified IgGs were considered suitable for biological tests when aggregate rates were below 5\%. Limulus Amebocyte Lysate (LAL) endotoxin test Gel Clot method was further used to test purified IgGs for the presence of endotoxins. Endotoxin levels of the purified IgGs were below $7 \mathrm{UI} / \mathrm{mg}$.

\section{FCRn BINDING OF IgG VARIANTS BY SURFACE PLASMON RESONANCE}

The interaction of IgG variants produced in $\mathrm{Y} 2 \mathrm{~B} / 0$ with immobilized recombinant human FcRn was monitored by surface plasmon resonance (SPR) detection on a BIAcore X100 instrument using a CM5 sensor chip (BIAcore, GE Healthcare), as previously described (41). All measurements were performed at $25^{\circ} \mathrm{C}$ with IgG concentrations ranging from 1 to $200 \mathrm{nM}$ at a flow rate of $10 \mu \mathrm{l} / \mathrm{min}$. IgGs were diluted in PBS/Tween-20 (50 mM sodium phosphate, $\mathrm{pH} 6.0,150 \mathrm{mM} \mathrm{NaCl}, 0.02 \% \mathrm{NaN}_{3}, 0.01 \%$ Tween-20), which is used as running buffer in equilibrium binding experiments. Data were collected for $10 \mathrm{~min}$ and a $1 \mathrm{~min}$ pulse of PBS, $\mathrm{pH} 8.0$ containing $0.05 \%$ Tween- 20 was used to regenerate surfaces. The equilibrium RU observed for each injection was plotted against the IgG concentration. The equilibrium $K_{\mathrm{D}}$ values were 
determined using the steady-state affinity model included in the BIA evaluation software version 3.1.

\section{ADCC ACTIVITY}

Human natural killer cells (NK cells) were purified from the peripheral blood of healthy volunteer donors by the negative depletion technique developed by Miltenyi. The ADCC test comprises incubating the NK cells with CD20-expressing Raji target cells, in the presence of different concentrations of anti-CD20 antibodies. After $16 \mathrm{~h}$ of incubation, the cytotoxicity induced by the anti-CD20 antibodies was measured by quantifying in cell supernatants the level of the intracellular enzyme lactate dehydrogenase $(\mathrm{LDH})$ released from lysed target cells. The specific lysis results are expressed as the percentage of lysis as a function of antibody concentration. $\mathrm{EC}_{50}$ values (antibody concentration inducing $50 \%$ of maximum lysis induced by the IgG-WT) and Emax (percentage of maximum lysis) were calculated using the software GraphPad PRISM.

\section{CDC ACTIVITY}

The CD20-expressing Raji target cells were incubated with different concentrations of anti-CD2 0 antibodies $(0-5,000 \mathrm{ng} / \mathrm{ml})$ in the presence of baby rabbit serum as a source of complement (Cedarlane, dilution to $1 / 10$ ). After $1 \mathrm{~h}$ of incubation at $37^{\circ} \mathrm{C}$, the level of $\mathrm{LDH}$ released in the supernatant by the lysed target cells was measured chromogenically (Roche Applied Sciences Cytotoxicity Detection Kit) and used to quantify the complement-dependent cytotoxicity mediated by the antibodies. The results were expressed as a percentage of lysis. $\mathrm{EC}_{50}$ (quantity of antibody that induces $50 \%$ of maximum lysis) and $E_{\max }$ (percentage of maximum lysis) were calculated using the software GraphPad PRISM.

\section{PRODUCTION OF IgG VARIANTS IN HEK293-F CELLS}

The Fc WT and variants were cloned into the eukaryotic expression vector pMGM05-CD20 as a BamHI/NotI fragment using standard PCR protocols. The pMGM05-CD20 vector is derived from pCEP4 (Invitrogen) and contains the heavy chain of the anti-CD20 antibody previously expressed in Y2B/0 cells [based on the Fv domain of CAT 13.6E12 (50)]. The light chain of this antibody was inserted into a similar vector derived from pCEP4 (pMGM01-CD20). FreeStyle ${ }^{\mathrm{TM}}$ HEK293-F cells (Invitrogen), cultured in 24-well plates, were co-transfected with pMGM01-CD20 and pMGM05-CD20 vectors (Fc-WT and variants) in equimolar amounts $(250 \mathrm{ng} / \mathrm{ml})$ with FreeStyle ${ }^{\mathrm{TM}}$ MAX reagent $(1 \mu \mathrm{l} / \mathrm{ml})$ using standard protocols (Invitrogen). Cells were cultured in suspension in serum-free medium for 7 days post-transfection and supernatants $(1 \mathrm{ml})$ containing IgG were harvested after centrifugation of the cells at $100 \mathrm{~g}$ for $10 \mathrm{~min}$. IgG secreted in the supernatants were quantified using an ELISA assay on recombinant protein L (Pierce), with purified anti-CD20 antibody produced in HEK293-F cells used as standard. Supernatants and standard antibody, serially diluted in PBS/0.05\% Tween-20, were tested on Maxisorp immunoplates (Nunc) previously coated with $0.25 \mu \mathrm{g}$ protein L/well and blocked with 5\% skimmed milk in PBS. After incubation for $1 \mathrm{~h}$ at $37^{\circ} \mathrm{C}$, wells were washed three times with PBS/0.05\% Tween-20. Bound IgG variants were detected with an HRP goat anti-human IgG $\left(\gamma\right.$ chain specific) $\mathrm{F}\left(\mathrm{ab}^{\prime}\right)_{2}$ fragment (Sigma). IgG variants produced were quantified $(1-4 \mu \mathrm{g} / \mathrm{ml})$ using the standard curve.

\section{ELISA TESTS OF IgG VARIANTS PRODUCED IN THE SUPERNATANTS OF HEK293-F CELLS}

The IgG variants were tested for their binding to the human complement $\mathrm{C} 1 \mathrm{q}$ and several human Fc receptors by ELISA: C1q complement (Calbiochem), Fc $\gamma$ RIIIA-V158 (R\&D system), FcRnp3, Fc $\gamma$ RIIA-R131 (R\&D system), and Fc $\gamma$ RIIB (R\&D system). ELISA tests were performed in PBS for all effector molecules except for FcRn, which was realized in P6. Maxisorp immunoplates were coated with $0.5 \mu \mathrm{g} \mathrm{C1q}$ complement/well in PBS, $0.1 \mu \mathrm{g}$ Fc $\gamma$ RIIIAV158/well in PBS, or $0.1 \mu \mathrm{g}$ FcRn-p3/well in P6. Immobilizer nickel chelate plates (Nunc) were coated with $0.1 \mu \mathrm{g}$ Fc $\gamma$ RIIA$\mathrm{R} 131 /$ well or $0.4 \mu \mathrm{g} \mathrm{Fc} \gamma \mathrm{RIIB} /$ well in $0.01 \mathrm{M} \mathrm{KCl}$. After coating overnight at $4^{\circ} \mathrm{C}$, plates were washed two times with $\mathrm{PBS} / 0.05 \%$ Tween-20 (or P6/0.05\% Tween-20 for FcRn) and saturated with $\mathrm{PBS} / 4 \%$ BSA (or P6/4\% BSA for FcRn) for $2 \mathrm{~h}$ at $37^{\circ} \mathrm{C}$. In parallel, supernatants were diluted in PBS to a final IgG concentration of $0.5 \mu \mathrm{g} / \mathrm{ml}$ (or diluted in $\mathrm{P} 6$ to $0.3 \mu \mathrm{g} / \mathrm{ml}$ for the FcRn-binding test) and mixed with HRP $\mathrm{F}\left(\mathrm{ab}^{\prime}\right)_{2}$ goat anti-human $\mathrm{F}\left(\mathrm{ab}^{\prime}\right)_{2}$ at the same concentration for $2 \mathrm{~h}$ at room temperature. $\mathrm{F}\left(\mathrm{ab}^{\prime}\right)_{2}$-aggregated IgGs were then incubated under gentle agitation for $1 \mathrm{~h}$ at $30^{\circ} \mathrm{C}$ on the saturated ELISA plates without dilution for C1q, Fc $\gamma$ RIIAR131, and Fc $\gamma$ RIIB (i.e., IgGs at $0.5 \mu \mathrm{g} / \mathrm{ml}$ ), diluted in PBS to $0.25 \mu \mathrm{g} / \mathrm{ml}$ for Fc $\gamma$ RIIIA-V158 or diluted in P6 to $0.0375 \mu \mathrm{g} / \mathrm{ml}$ for FcRn-p3. Plates were then revealed with TMB (Pierce) and absorbance read at $450 \mathrm{~nm}$.

\section{RESULTS \\ RANDOM MUTAGENESIS TO INCREASE FcRn BINDING Use of MutaGen ${ }^{T M}$ and phage display technologies}

The human IgG1 Fc gene encoding amino acid residues 226447 (referred to as Fc-WT, for Fc Wild Type) was cloned into our modified phagemid vector (51). This Fc-WT molecule comprises the five most $\mathrm{C}$-terminal amino acids of the hinge region and the entire $\mathrm{CH} 2$ and $\mathrm{CH} 3$ domains. In our previous study (41), several fully randomized libraries were generated using low fidelity human DNA polymerases to introduce random mutations homogeneously throughout the entire gene without any hot spot (MutaGen ${ }^{\mathrm{TM}}$ technology). Fc variants with improved FcRn binding were then isolated from these Fc-libraries using a $\mathrm{pH}$-dependent phage display selection on human recombinant FcRn. Briefly, FcRn binding and washing steps were performed at $\mathrm{pH} 6.0$ whereas bound Fc-phages were eluted at $\mathrm{pH} 7.4$ to preserve $\mathrm{Fc} / \mathrm{FcRn}$ interaction $\mathrm{pH}$ dependency, which is crucial for its physiological role. Two successive rounds of mutagenesis and selection (called MS1 and MS2) were performed to cumulate Fc mutations with a positive impact on Fc/FcRn interaction. Thus, for the MS2 step, the DNA template used to construct random libraries was a DNA pool of 42 variants with improved FcRn binding by phage-ELISA selected during the MS1 step.

Throughout MS1 and MS2 rounds, $500 \mathrm{Fc}$ variants were isolated and ranked according to their FcRn-binding properties using a comparative phage-ELISA assay at $\mathrm{pH}$ 6.0. To set up this experiment, the double variant T250Q/M428L (Fc-QL) (17) and the triple mutant M252Y/S254T/T256E (Fc-YTE) (15) were constructed as positive controls. In this phage-ELISA assay (at $\mathrm{pH}$ 6.0) on human recombinant FcRn, the Fc-QL, and Fc-YTE control variants, expressed on the M13 bacteriophage, had a specific 
signal threefold stronger than the Fc-WT (average ratio of 3.2 for Fc-QL and 3.5 for Fc-YTE). As expected, none of the control variants Fc-QL and Fc-YTE nor the Fc-WT showed any binding at $\mathrm{pH} 7.4$ (data not shown). During the MS1 round, a total of 227 different Fc variants were isolated, 139 were considered positive with a ratio/Fc-WT $>2$ and 73 were better than the positive control Fc-QL (ratio/Fc-WT >3.2). The best clone, S5A-41, had a ratio/Fc-WT of 9.0. During the MS2 round, 223 different mutated clones were isolated. Since the difference between the signals of the Fc-WT and the Fc variants was too great to be directly compared, these variants were ranked using a comparative phage-ELISA assay against the Fc-QL variant as reference. The best Fc variant isolated during MS1, S5A-41, was used as positive control on each phage-ELISA plate, its ratio/FcQL was 3.9 ( \pm 0.6$)$. Among the $223 \mathrm{Fc}$ variants tested, $209 \mathrm{Fc}$ variants were better than the Fc-QL and $39 \mathrm{Fc}$ variants were

Table 1 | Characterization of Fc variants isolated during the MS2 process

\begin{tabular}{|c|c|c|}
\hline $\begin{array}{l}\text { Fc } \\
\text { variants }\end{array}$ & Mutations & $\begin{array}{l}\text { Ratio/ } \\
\text { Fc-QL }\end{array}$ \\
\hline C6A-69 & T307A/N315D/A330V/E382V/N389T/N434Y & 8.9 \\
\hline C6A-78 & T256N/A378V7S383N/N434Y & 8.7 \\
\hline T5A-74 & N315D/A330V/N361D/A378V/N434Y & 8.6 \\
\hline C6A-74 & V259I/N315D/N434Y & 8.5 \\
\hline C6A-60 & $\mathrm{P} 230 \mathrm{~S} / \mathrm{N} 315 \mathrm{D} / \mathrm{M} 428 \mathrm{~L} / \mathrm{N} 434 \mathrm{Y}$ & 8.4 \\
\hline T5A-58 & F241L/N264E/T307P/A378V/H433R & 8.1 \\
\hline C6A-72 & T250A/N389K/N434Y & 8.0 \\
\hline T5A-93 & V305A/N315D/A330V/P395A/N434Y & 8.0 \\
\hline T5A-78 & V264E/Q386R/P396L/N434S/K439R & 8.0 \\
\hline T5A-87 & N315D/A330V/O362R/N434Y & 7.8 \\
\hline C6A-66 & E294del/T307P/N434Y & 7.7 \\
\hline C6A-85 & V305A/N315D/A330V/N389K/N434Y & 7.4 \\
\hline C8A-15 & N315D/A327V/A330VA/397M/N434Y & 7.4 \\
\hline T5A-89 & $\mathrm{P} 230 \mathrm{~T} / \mathrm{F} 241 \mathrm{~L} / \mathrm{N} 264 \mathrm{E} / \mathrm{D} 265 \mathrm{G} / \mathrm{A378V} / \mathrm{N} 421 \mathrm{~T}$ & 7.1 \\
\hline T7A-92 & V264E/P396L/S415N/N434S & 6.7 \\
\hline T6A-57 & $\mathrm{P} 227 \mathrm{~L} / \mathrm{N} 264 \mathrm{E} / \mathrm{A} 378 \mathrm{~V} / \mathrm{N} 434 \mathrm{~S}$ & 6.4 \\
\hline T5A-94 & V264E/A378T/P396L & 5.8 \\
\hline T6A-75 & P230T/N315D/O362R/S426T/N434Y & 5.7 \\
\hline C3A-13 & C226G/N315D/A330V/N434Y & 5.6 \\
\hline T5A-55 & P230L/F241L/F243L/N264E/T307P/A378V & 5.6 \\
\hline S5A-41 & P230T/V303A/K322R/N389T/F404L/N434S & 3.9 \\
\hline T6A-21 & N315D/A378V/N434Y & 3.1 \\
\hline T4A-04 & N315D/A330V/E382V/N434Y & 3.0 \\
\hline С3A-01 & N315D/A330V/N434Y & 2.5 \\
\hline C3A-03 & N315D/N434Y & 2.0 \\
\hline C6A-05 & T307A/N315D/A330V/N434Y & 1.9 \\
\hline M3A-01 & N361D/N434Y & 1.4 \\
\hline
\end{tabular}

Mutations and phage-ELISA ratios obtained for the 20 best FC variants of MS2 compared with the positive control FC-QL (upper part of the Table). The six variants chosen to be further characterized are in bold. Below the S5A-41 variant are listed the $F_{C}$ variants that were characterized during MS2 and are combinations of two to four mutations also found in our six preferred variants (lower part of the table). better than the S5A-41 variant. Sequences and phage-ELISA results obtained for the 20 best Fc variants from MS2 in comparison with the S5A-41 variant are detailed in the upper part of Table 1. To compare the variants from MS2 with the variants from MS1, an estimated ratio/Fc-WT was calculated by multiplying the ratio/Fc-QL of the variants with the ratio/Fc-WT of the Fc-QL $(=3.2 \pm 0.3)$ determined during MS1 (ratio/Fc$\mathrm{WT}=3.2 \times$ ratio/Fc-QL). Using this calculation, the S5A-41 variant had a ratio/Fc-WT of 12.5 instead of 9.0 when tested directly in comparison with the Fc-WT during the MS1. Ranking of significant Fc variants from MS1 and MS2 using this calculation is illustrated in Table 2 .

Table 2 | Comparison of Fc variants selected during MS1 and MS2.

\begin{tabular}{|c|c|c|c|}
\hline $\begin{array}{l}\text { Fc } \\
\text { variants }\end{array}$ & Mutations & $\begin{array}{l}\text { Ratio/ } \\
\text { Fc-WT }\end{array}$ & $\begin{array}{l}\text { Variant } \\
\text { origin }\end{array}$ \\
\hline C6A-69 & $\begin{array}{l}\text { T307A/N315D/A330V/E382V/ } \\
\text { N389T/N434Y }\end{array}$ & 28.4 & MS2 \\
\hline C6A-78 & T256N/A378V/S383N/N434Y & 27.8 & MS2 \\
\hline C6A-78A & T256N/A378V/N434Y & 27.8 & $\begin{array}{l}\mathrm{MS} 2+ \\
\text { mutagenesis }\end{array}$ \\
\hline T5A-74 & $\begin{array}{l}\text { N315D/A330V/N361D/A378V/ } \\
\text { N434Y }\end{array}$ & 27.6 & MS2 \\
\hline C6A-74 & V259I/N315D/N434Y & 27.2 & MS2 \\
\hline C6A-60 & P230S/N315D/M428L/N434Y & 26.8 & MS2 \\
\hline C6A-66 & E294del/T307P/N434Y & 24.6 & MS2 \\
\hline T6A-21 & N315D/A378V/N434Y & 10.0 & MS2 \\
\hline T4A-04 & N315D/A330V/E382V/N434Y & 9.6 & MS2 \\
\hline S5A-41 & $\begin{array}{l}\mathrm{P} 230 \mathrm{~T} / \mathrm{V} 303 \mathrm{~A} / \mathrm{K} 322 \mathrm{R} / \mathrm{N} 389 \mathrm{~T} / \\
\mathrm{F} 404 \mathrm{~L} / \mathrm{N} 434 \mathrm{~S}\end{array}$ & $\begin{array}{l}9.0 \\
(12.5)\end{array}$ & MS1 \\
\hline C3A-01 & N315D/A330V/N434Y & 8.0 & MS2 \\
\hline C3A-03 & N315D/N434Y & 6.4 & MS2 \\
\hline C6A-05 & T307A/N315D/A330V/N434Y & 6.1 & MS2 \\
\hline S4A-02 & A378V/N434Y & 4.6 & MS1 \\
\hline M3A-01 & N361D/N434Y & 4.5 & MS2 \\
\hline L6B-41 & P230S/M428L & 4.4 & MS1 \\
\hline S4A-11 & N389T/N434Y & 3.7 & MS1 \\
\hline S3A-35 & N434Y & 3.5 & MS1 \\
\hline B4A-13 & P228L & 3.5 & MS1 \\
\hline B3A-32 & $\mathrm{P} 228 \mathrm{R}$ & 3.1 & MS1 \\
\hline B5A-35 & P230S & 2.8 & MS1 \\
\hline S3A-05 & N434S & 2.7 & MS1 \\
\hline B4A-22A & A378V & 2.6 & $\begin{array}{l}\text { MS1 + } \\
\text { mutagenesis }\end{array}$ \\
\hline B5A-25B & N315D & 2.1 & $\begin{array}{l}\text { MS1+ } \\
\text { mutagenesis }\end{array}$ \\
\hline B5A-15 & M428L & 2.0 & MS1 \\
\hline S3A-25A & V264E & 1.9 & $\begin{array}{l}\text { MS1+ } \\
\text { mutagenesis }\end{array}$ \\
\hline L3A-01 & $\mathrm{T} 256 \mathrm{~N}$ & 1.8 & MS1 \\
\hline B3A-17 & T307A & 1.3 & MS1 \\
\hline
\end{tabular}

Mutations and phage-ELISA ratios obtained in comparison with the FC-WT. Analysis of the single mutations and the different combinations of mutations allowed us to ascertain the impact of the mutations included in our six preferred variants. 


\section{Data mining using results from random mutagenesis and phage-ELISA}

Given the high number of positive clones isolated, a data base was constructed to store and analyze the DNA sequences and the phage-ELISA results obtained for the Fc variants isolated during MS1 and MS2 processes. Sequence analysis of the positive Fc variants (i.e., variants with a ratio/Fc-WT $>2$, corresponding to 139 variants from MS1 and 219 variants from MS2) identified the following 9 key positions, which are positions mutated in more than $10 \%$ of the improved Fc variants: P230, F241, V264, T307, N315, A330, A378, N389, and N434. Remarkably, the position N434 is mutated in almost $80 \%$ of the positive variants, whereas positions V264, N315, and A378 are mutated in more than $40 \%$ of the positive variants (41). These findings are clearly noticeable for the 20 best Fc variants listed in Table 1, which all comprise 2-3 key positions combined with 1-3 other mutations (4.45 mutated amino acids on average). From our Fc variants, we chose the five best variants (C6A-69, C6A-78, T5A-74, C6A-74, and C6A-60) as well as the C6A-66 variant for more thorough characterization (in bold in Tables 1 and 2). The latter was selected for its originality to contain an amino acid deletion (E294Del). Data mining from our data base showed that many Fc variants isolated from MS1 and MS2 were combinations of one to four mutations also found in our six selected variants ( six Fc variants from MS2, lower part of Table 1 and Fc variants from MS1 and MS2 assembled in Table 2). This allowed us to verify by comparison if each mutation included in our six selected variants had a real positive effect on the FcRn binding. In case that no appropriate variant for comparison was available, new variants were generated by directed mutagenesis to reveal the impact of associated mutations. The resulting variants were named as the parental clone with a letter added at the end of the name (Table 2 ).

The C6A-60 variant comprises four mutations (P230S/N315D/ $\mathrm{M} 428 \mathrm{~L} / \mathrm{N} 434 \mathrm{Y}$ ) each of which is present as single mutations in the Fc variants B5A-35 (P230S), B5A-25B (N315D), B5A-15 (M428L), and S3A-35 (N434Y) and where they had a direct impact on FcRn binding, with ratios/Fc-WT ranging from 2 to 3.5 each. The C6A60 variant is also a combination of the two double variants L6B-41 (P230S/M428L) and C3A-03 (N315D/N434Y), which both display additive effects of the single mutations (ratios/Fc-WT of 4.4 and 6.4, respectively). Conversely, the final combination of the 4 mutations, C6A-60 exhibits synergistic effects with a ratio/Fc-WT $>25$, instead of $10-15$ in case of additive effects of the mutations. The C6A-74 variant comprises the double variant C3A-03 (N315D/N434Y) as well, with the addition of one mutation, V259I that was never seen in another Fc variant but has a great impact on $\mathrm{Fc} / \mathrm{FcRn}$ binding, increasing the ratio/Fc-WT from 6.4 to more than 25. The T5A-74 variant is composed of five mutations, three of which have been tested as single mutations in the $\mathrm{Fc}$ variants B5A-25B (N315D), B4A-22A (A378V), and S3A-35 (N434Y) and have demonstrated a positive impact on $\mathrm{Fc} / \mathrm{FcRn}$ interaction. The impact of the N361D mutation is confirmed by comparison of the variants M3A-01 (N361D/N434Y) and S3A-35 (N434Y). Likewise, the contribution of the $\mathrm{A} 330 \mathrm{~V}$ mutation is confirmed by comparison of the variants C3A-03 (N315D/N434Y) and C3A01 (N315D/A330V/N434Y). The C6A-78 variant comprises four mutations, three of which exert a positive effect as shown in the variants L3A-01 (T256N), B4A-22A (A378V), and S3A-35 (N434Y). The last mutation, N383S, was not included in any other variant and its removal, C6A-78A variant, seems to have no effect on FcRn binding. This mutation was therefore identified as unnecessary to improve FcRn binding. This result was confirmed by SPR with purified IgG variants (Table 4) and, therefefore, C6A-78 variant was replaced by C6A-78A in the subsequent tests. Finally, the C6A-69 variant includes six mutations, three of which were shown to have a positive effect in the mutation variants $\mathrm{B} 3 \mathrm{~A}-17$ (T307A), B5A-25B (N315D), and S3A-35 (N434Y). The impact of the A330V was described above for the T5A-74 variant. The comparison of the S4A-11 (N389T/N434Y) and S3A-35 (N434Y) variants suggests a modest contribution for the N389T mutation that needs to be confirmed. The impact of the E382V mutation is confirmed by comparison of the C3A-01 (N315D/A330V/N434Y) and T4A-04 (N315D/A330V/E382V/N434Y) variants.

Overall, these data permitted to confirm the direct contribution of most of the key positions identified previously by sequence analyses: P230, T307, N315, A330, A378, and N434. Moreover, the key position V264E, which is not found in our six best variants, was also tested as a single mutation, and a ratio/Fc-WT of 1.9 was obtained. Interestingly, these analyses also permitted the identification of a position in the hinge region, P228 that induces a significant FcRn binding increase when mutated to L or $\mathrm{R}$ (ratio/Fc-WT of 3.5 and 3.1, respectively). This position was not identified as a key position but displays the strongest FcRn binding increase as a single mutation, similarly to the crucial position N434, mutated to Y or S (ratio/Fc-WT of 3.5 and 2.7, respectively).

\section{Distribution of the identified mutations on the Fc sequence}

The amino acids previously identified were visualized on a $3 \mathrm{D}$ representation of the IgG1 Fc fragment modeled using crystallographic data (52) and Discovery Studio software (positions in red sticks, right panel of Figure 1). In parallel, the residues that have been involved in the Fc/FcRn interaction by crystallography (14) and directed mutagenesis $(13,53)$ were positioned on an analogous $3 \mathrm{D}$ representation. The FcRn-binding site encompasses three distinct zones in the Fc fragment at the interface between the $\mathrm{CH} 2$ and $\mathrm{CH} 3$ domains: residues 252-254,307-311 in the $\mathrm{CH} 2$ domain, and residues 433-436 in the $\mathrm{CH} 3$ domain (positions in purple ribbon, left panel of Figure 1). Using this structural knowledge, several Fc variants with increased FcRn affinity have been obtained by alanine scanning (13), directed mutagenesis $(15,21)$, and in silico approaches (16-18) albeit focusing on the FcRn-binding site. These optimized Fc variants, developed by other groups, mainly include the residues T250, M252, S254, T256, V259, T307, V308, M428, H433, and N434 (positions in purple sticks, left panel of Figure 1), all located inside the FcRn-binding site. In contrast, the random mutagenesis method used to generate our Fc variants allowed to identify positions distributed over the whole Fc region. Among the positions identified, two are directly in the FcRn-binding site, one in the $\mathrm{CH} 2$ domain (T307), and the other in the $\mathrm{CH} 3$ domain (N434) and have been largely described previously $(13,18,20)$. Three positions are close to the FcRn-binding site, one in the $\mathrm{CH} 2$ domain (N315), and the two others (A378 and N389) in the $\mathrm{CH} 3$ domain. Finally, five positions are located outside the FcRn-binding site: P228 and P230 in the lower hinge 

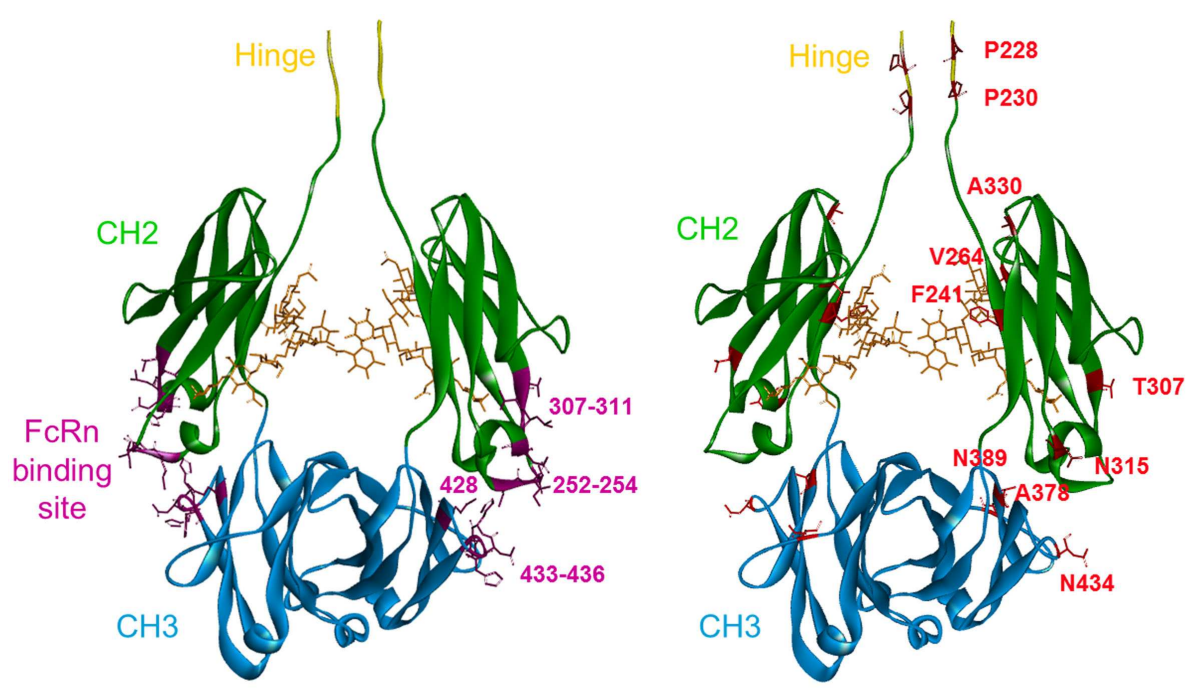

FIGURE 1 | 3D representation of a model of the Fc fragment from the human IgG1 made with Discovery Studio software The last five amino acids of the hinge region are in yellow. The $\mathrm{CH} 2$ domain is in green and the $\mathrm{CH} 3$ domain is in blue. Left panel: in purple, the FcRn-binding site in the $\mathrm{CH} 2-\mathrm{CH} 3$ interdomain region, with the main positions used by others to increase FcRn binding highlighted: T250, M252, S254, T256, V259, T307, M428, H433, and N434. Right panel: the key positions identified in our study are highlighted in red. These mutations are distributed over the entire Fc sequence. region and F241, V264, and A330 in the upper part of the $\mathrm{CH} 2$ domain. The mutations identified on these positions probably have a positive long-range effect on the overall structure of the $\mathrm{Fc}$ domain favoring the $\mathrm{Fc} / \mathrm{FcRn}$ complex.

\section{DIRECTED MUTAGENESIS TO INCREASE FCRn BINDING}

Unexpectedly, the use of random mutagenesis and phage display selection revealed the contribution of mutations located in the $\mathrm{Fc}$ hinge domain on $\mathrm{Fc} / \mathrm{FcRn}$ binding (P228R or L and P230S). Since these mutations were rarely used in our optimized variants, we combined them with our five best variants C6A-69, C6A-78A, T5A-74, C6A-74, and C6A-60 in an attempt to further increase their FcRn binding. New variants were constructed using directed mutagenesis by adding in the hinge region one or two mutations as follow: P230S, P228L, P228R, P228L/P230S, or P228R/P230S. These new variants were named based on the parental variant with a letter added at the end of the name (AG) (Table 3). They were tested using phage-ELISA assay at $\mathrm{pH}$ 6.0 and result of each new variant was directly compared to its parental molecule to estimate the influence of the added mutation(s) (ratio new variant/parental variant). Depending on the parental variant, the results observed were very heterogeneous as the mutations displayed unpredictable and sometimes opposite effects. For instance, the mutation P228L could either have a negative (C6A-69 and C6A-60), a neutral (T5A-74), or a modest positive effect (C6A-78 and C6A-74). The mutations P230S, $\mathrm{P} 228 \mathrm{~L} / \mathrm{P} 230 \mathrm{~S}$, and $\mathrm{P} 228 \mathrm{R} / \mathrm{P} 230 \mathrm{~S}$ had mostly negative or neutral effects, with the exception of the combination of P228R/P230S with T5A-74 (twofold increase). Finally, the mutation P228R was the most efficient mutation with a neutral effect on two variants (C6A-69 and C6A-60) and a positive effect on three variants (C6A78 , T5A-74, and C6A-74), with ratios ranging from 2.2- to 3.3-fold increase compared to the parental molecule. These results exemplify the difficulty of designing optimized variants by directed mutagenesis, the resulting effect of the combination of several positive mutations being often unpredictable.

Successful combinations based on the parental variant C6A78 were selected to be further characterized. IgG-WT and variants C6A-78, C6A-78A, C6A-78B, and C6A-78D were produced as fulllength IgGs with the variable regions of the chimeric anti-human CD20 CAT 13.6E12 in Y2B/0 cells as described before (41). FcRn affinities of these IgGs were measured by SPR on immobilized recombinant human FcRn at $\mathrm{pH} 6.0$ (Table 4). In this assay, the $K_{\mathrm{D}}$ values of the four IgG variants ranged from 19.8 to $33.1 \mathrm{nM}$ as compared to $101.0 \mathrm{nM}$ for the IgG-WT. This experiment confirmed that the C6A-78A variant has a similar affinity as C6A-78, albeit having one mutation less (N383S) and that the C6A-78B variant displays a slightly increased affinity. However, the positive impact of the mutation P228R (C6A-78D) was not confirmed. In the IgG molecule, this position P228 may be more constrained than in the phage display system, impeding the substitution by the arginine, whereas the substitution by the leucine seems to conserve a positive impact.

\section{IMPACT OF MUTATIONS INCREASING FCRn BINDING ON EFFECTOR FUNCTIONS} IgG variants produced in $\mathrm{Y} 2 \mathrm{~B} / \mathrm{O}$ cells

Together with the IgG-WT and the four IgG variants described above, IgG-YTE and the selected variants C6A-69, T5A-74, C6A74, C6A-60, and C6A-66 were also produced as full-length IgGs with the variable regions of the chimeric anti-human $\mathrm{CD} 20$ CAT 13.6E12 (50). To combine the advantages of glyco- and protein-Fc engineering, these IgGs variants were produced in YB2/0 cells (EMABling ${ }^{\circledR}$ platform), permitting low fucosylation 
Table 3 | Comparison of Fc variants generated by directed mutagenesis to increase FcRn binding.

\begin{tabular}{|c|c|c|c|}
\hline $\begin{array}{l}\text { Fc } \\
\text { variants }\end{array}$ & Mutations & $\begin{array}{l}\text { Ratio } \\
\text { variant/ } \\
\text { parental } \\
\text { variant }\end{array}$ & SD \\
\hline C6A-69E & P228R/C6A-69 & 1.1 & 0.3 \\
\hline C6A-69 & T307A/N315D/A330V/E382V/N389T/N434Y & 1.0 & 0.2 \\
\hline C6A-69C & P230S/C6A-69 & 0.9 & 0.1 \\
\hline C6A-69D & P228L/C6A-69 & 0.5 & 0.1 \\
\hline C6A-78D & $\mathbf{P 2 2 8 R} / C 6 A-78 A$ & 3.3 & 0.8 \\
\hline C6A-78B & P228L/C6A-78A & 1.7 & 0.2 \\
\hline C6A-78F & P228R/P230S/C6A-78A & 1.1 & 0.2 \\
\hline C6A-78C & $\mathbf{P 2 3 0 S} / \mathrm{C} 6 \mathrm{~A}-78 \mathrm{~A}$ & 1.1 & 0.3 \\
\hline C6A-78A & T256N/A378V/N434Y & 1.0 & 0.1 \\
\hline C6A-78E & P228L/P230S/C6A-78A & 0.7 & 0.0 \\
\hline T5A-74D & $\mathbf{P 2 2 8 R} / T 5 A-74$ & 3.0 & 0.7 \\
\hline T5A-74F & P228R/P230S/T5A-74 & 2.0 & 0.6 \\
\hline T5A-74 & N315D/A330V/N361D/A378V/N434Y & 1.0 & 0.2 \\
\hline T5A-74C & $\mathbf{P 2 2 8 L} / \mathrm{T} 5 \mathrm{~A}-74$ & 0.9 & 0.2 \\
\hline T5A-74E & P228L/P230S/T5A-74 & 0.8 & 0.2 \\
\hline T5A-74B & $\mathbf{P 2 3 0 S} / 75 A-74$ & 0.7 & 0.2 \\
\hline C6A-74D & $\mathbf{P 2 2 8 R} / \mathrm{C} 6 \mathrm{~A}-74$ & 2.2 & 0.5 \\
\hline C6A-74C & P228L/C6A-74 & 1.3 & 0.3 \\
\hline C6A-74E & P228L/P230S/C6A-74 & 1.0 & 0.3 \\
\hline C6A-74 & V259I/N315D/N434Y & 1.0 & 0.2 \\
\hline C6A-74F & P228R/P230S/C6A-74 & 0.9 & 0.2 \\
\hline C6A-74A & $\mathbf{P 2 3 0 S / C 6 A - 7 4 ~}$ & 0.7 & 0.1 \\
\hline C6A-60 & P230S/N315D/M428L/N434Y & 1.0 & 0.2 \\
\hline C6A-60D & $\mathbf{P 2 2 8 R} / \mathrm{C} 6 \mathrm{~A}-60$ & 0.9 & 0.2 \\
\hline C6A-60C & P228L/C6A-60 & 0.6 & 0.2 \\
\hline
\end{tabular}

The positions in the hinge domain (P228 and P230) identified by random mutagenesis were combined with our five best variants using directed mutagenesis and resulted in further increased FCRn binding in phage-ELISA assays.

of the IgG glycan moiety resulting in enhanced ADCC as previously described for two antibodies in clinical development, the anti-CD20 mAb ublituximab (54-56), and the anti-RhD mAb roledumab $(57,58)$. All such produced IgG variants conserved the same antigen binding properties as the IgG-WT and contain $~ 35 \%$ of fucosylated glyco-forms (data not shown). As described above, SPR measures on immobilized FcRn confirmed the increased FcRn affinity for all our IgG variants (41). IgGs were then tested for their capacity to elicit ADCC with purified NK cells against CD20expressing target cells (Table 5, left column). As described before (41), our five best IgG variants displayed similarly high ADCC as the IgG-WT showing that they all have retained glyco-engineered improved ADCC activity. A slightly increased ADCC was even observed for the IgG variants C6A-74 and C6A-60 (x3.7 and x6.7, respectively). On the other hand, the C6A-66 variant, which contains the deletion of the amino acid E294, has completely lost ADCC activity. The C6A-78 and C6A-78A, differing from one mutation (N383S) that was confirmed to be dispensable for FcRn
Table 4 | SPR affinity measures at steady state on immobilized recombinant human FcRn of IgG-WT and variants produced in YB2/0 cells.

\begin{tabular}{llcc}
\hline IgG variants & Mutations & KD (nM) & $\begin{array}{c}\text { Ratio KD } \\
\text { WT/variant }\end{array}$ \\
\hline WT & None & 101.0 & 1.0 \\
C6A-78 & T256N/A378V/S383/N434Y & 33.1 & 3.1 \\
C6A-78A & T256N/A378V/N434Y & 26.1 & 3.9 \\
C6A-78B & P228L/T256N/A378V/N434Y & 19.8 & 5.1 \\
C6A-78D & P228R/T256N/A378V/N434Y & 25.3 & 4.0 \\
\hline
\end{tabular}

Table 5 | ADCC and CDC results of IgG-WT and IgG variants produced in YB2/0 cells.

\begin{tabular}{llcc}
\hline $\begin{array}{l}\text { IgG } \\
\text { variants }\end{array}$ & Mutations & $\begin{array}{l}\text { ADCC: } \\
\text { ratio EC50 } \\
\text { WT/variant }\end{array}$ & $\begin{array}{l}\text { CDC: ratio } \\
\text { EC50 WT/ } \\
\text { variant }\end{array}$ \\
\hline C6A-69 & T307A/N315D/A330V/E382V/N389T/ & 2.6 & $<0.1$ \\
& N434Y & & \\
C6A-78 & T256N/A378V/S383N/N434Y & 1.3 & 5.6 \\
C6A-78A & T256N/A378V/N434Y & 1.1 & 5.9 \\
C6A-78B & P228L7T256N/A378V/N434Y & 0.7 & 9.1 \\
C6A-78D & P228R/T256N/A378V/N434Y & 0.4 & 7.7 \\
T5A-74 & N315D/A330V/N361D/A378V/N434Y & 1.8 & $<0.1$ \\
C6A-74 & V259I/N315D/N434Y & 6.7 & 1.2 \\
C6A-60 & P230S/N315D/M428L/N434Y & 3.7 & 5.6 \\
C6A-66 & E294Del/T307P/N434Y & $<0.1$ & 0.6 \\
YTE & M252Y/S254T/T256E & 0.2 & $<0.1$ \\
\hline
\end{tabular}

Results are expressed as ratio $E C_{50}$ WT/variant. Increased ratios therefore correspond to an improved ADCC or CDC activity of the $I g G$ variant compared to the IgG-WT.

$0-0.7 ; 0.7-2 ; 2-10$

affinity, displayed similar ADCC. On contrary, the addition of mutations on position P228 seems to decrease ADCC, especially when arginine is used (C6A-78B and C6A-78D, $\mathrm{x} 0.7$ and 0.4 , respectively, compared to a ratio of 1.1 for $\mathrm{C} 6 \mathrm{~A}-78)$. Interestingly, the IgG-YTE variant, despite being mutated exclusively in the FcRn-binding site, has lost its ADCC activity.

Immunoglobulins $\mathrm{G}$ were also tested for their ability to induce $\mathrm{CDC}$ activity against $\mathrm{CD} 20$-expressing target cells in presence of baby rabbit serum (Table 5, right column). The level of CDC activity varies between IgG variants. C6A-78, C6A-78A, C6A-78B, C6A-78D, and C6A-60 variants have a CDC activity significantly higher than that of IgG-WT whereas C6A-69, T5A-74, and C6A-66 displayed low $\mathrm{CDC}$ activity. The CDC activity of C6A-74 variant is similar to that of IgG-WT. Moreover, the IgG-YTE variant has also lost CDC activity.

Overall, these results show that the selected variants for increased FCRn binding have different ADCC and CDC activities. One variant, C6A-60, has increased ADCC and CDC and one variant, C6A-74, has increased ADCC and conserved CDC. Two variants, C6A-69 and T5A-74, have conserved ADCC and low 
CDC. Two variants, C6A-78 and C6A-78A, have conserved ADCC and increased CDC. Two variants, C6A-78B and C6A-78D, have decreased ADCC and increased CDC. Finally, one variant (C6A66) has lost both ADCC and CDC activities, a feature also observed for the positive control IgG-YTE.

\section{IgG variants produced in HEK cells}

Using the same antigen specificity as previously described, IgGWT and variants were expressed in HEK293-F cells, a classical cell line, which produces IgGs with high fucose content (80-90\%) resulting in low ADCC as compared to IgGs produced in YB2/0 cells. To rapidly compare numerous variants for their binding properties to several Fc effectors (C1q, Fc $\gamma$ RIIIA-V158, Fc $\gamma$ RIIAR131, and FcyRIIB and FcRn), IgGs were produced in small quantities $(1 \mathrm{ml})$, titrated in cell supernatants, and directly tested by ELISA. Results for each receptor were expressed as a ratio of specific signal obtained for the IgG variant compared to the signal of the IgG-WT (Table 6). Our six previously selected IgG variants were tested thereby, with eight new improved combinations based on the results obtained by phage-ELISA (Table 3). Several positive controls were produced as well to set up the experiments. For FcRn, we used the IgG-QL and IgG-YTE variants described above but also the double variant M428L/N434S (Fc-LS) (18). The positive control for Fc $\gamma$ RIIIA was S239D/I332E (C1) (38), for the complement C1q; K326W/E333S (C3) (47), for Fc $\gamma$ RIIA; G236A (C4) (48), and for Fc $\gamma$ RIIB; S267E/L328F (C5) (49). Results for the positive controls $\mathrm{C} 1-\mathrm{C} 5$ are in agreement with published and patented data (US 2009/0042291 A1 and EP2386574 A2), validating our experimental setting. The $\mathrm{C} 1$ variant has increased binding for the three Fc $\gamma$ Rs tested. The $\mathrm{C} 3$ and $\mathrm{C} 4$ variants are selectively improved for one receptor each, the complement $\mathrm{Clq}$ and the Fc $\gamma$ RIIA, respectively. The C5 variant binding is largely improved for Fc $\gamma$ RIIB but also Fc $\gamma$ RIIA-R131. As expected, the three positive controls IgG-LS, -QL, and -YTE display increased FcRn-binding ability (ratios 4.46, 2.39, and 2.06, respectively). All our improved IgG variants demonstrate similar increase (ratios between 2.83 and 4.72 ), with no significant differences. This ELISA assay was not discriminant enough to reveal potential slight differences between the variants for their FcRn binding. Interestingly, the IgG-YTE demonstrated a decreased binding capacity to the complement $\mathrm{C} 1 \mathrm{q}$ and to the three Fc $\gamma$ Rs tested, in correlation with the functional results obtained with IgGs produced in YB2/0 cells (Table 5). Our variants display diverse binding patterns: selective decrease for FcyRIIIA (C6A-60), decrease for all the receptors (C6A-66, C6A-69, and C6A-69E), no change for any receptor (C6A-74, C6A$74 \mathrm{C}$, and C6A-74D), slight increase for all the receptors (C6A-78,

Table 6 | Binding cartography of IgG variants produced in HEK293 cells on the complement C1q, Fc $\gamma$ RIIIA-V158, Fc $\gamma R$ IIIA-R131, Fc $\gamma R I I B$, and FcRn

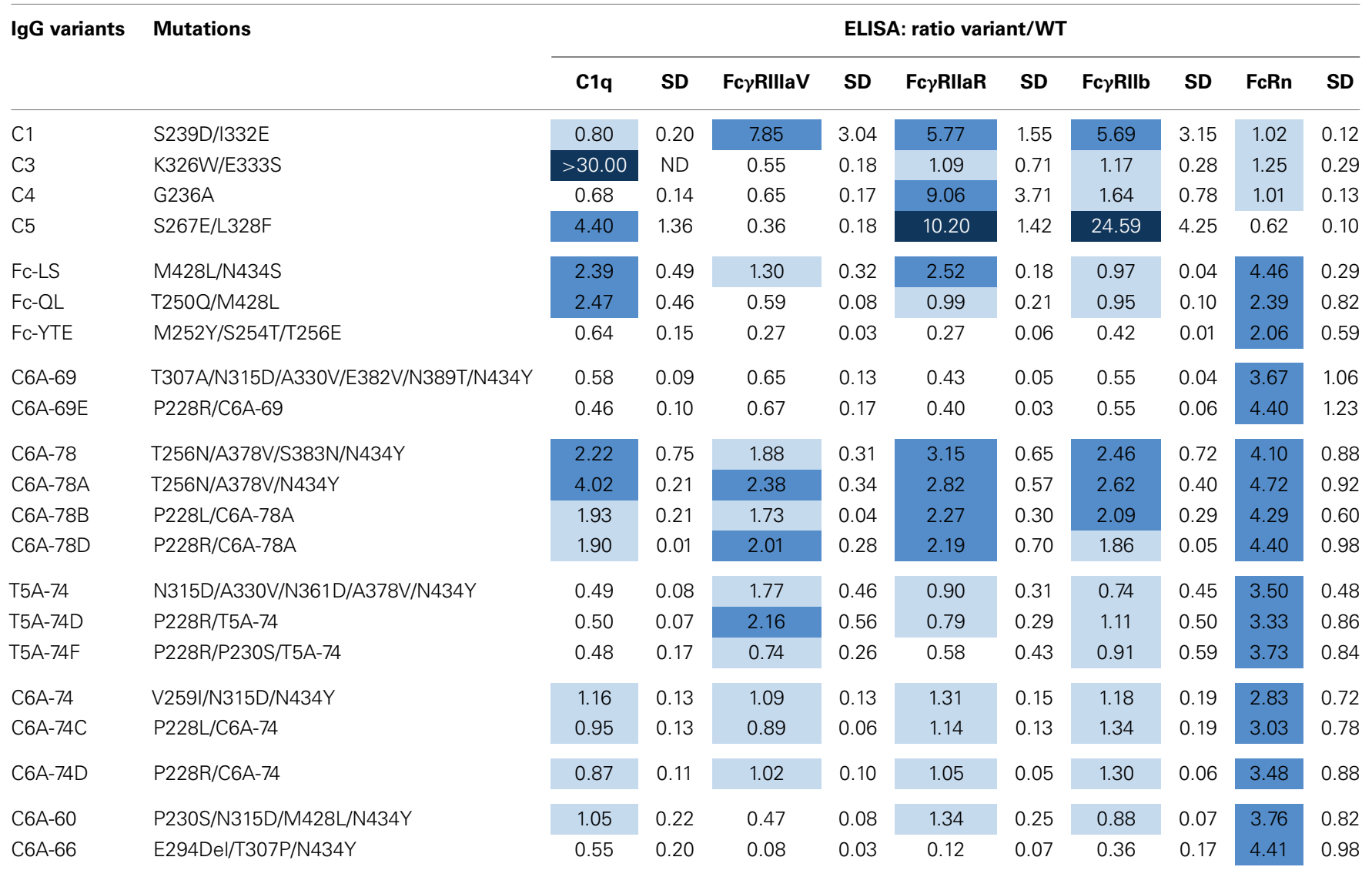

Results are expressed as ratio variantWT. Increased ratios therefore correspond to improved binding on to the receptor as shown by ELISA assay. $0-0.7 ; 0.7-2 ; 2-10 ;>10$. 
C6A-78A, C6A-78B, and C6A-78D), and decrease for the complement C1q binding (T5A-74, T5A-74D, and T5A-74F). The complement $\mathrm{C} 1 \mathrm{q}$ binding results are in good correlation with the CDC results obtained with IgGs produced in YB2/0 cells. Conversely, Fc $\gamma$ RIIIA binding results are significantly different from the ADCC results previously obtained (Table 5). For instance, C6A-60 and C6A-74, which displayed increased ADCC as lowfucose molecules, demonstrate decreased or conserved Fc $\gamma$ RIIIA binding, respectively, when produced in HEK293 cells. Altogether, in accordance to what we observed for the IgG molecules produced in $\mathrm{Y} 2 \mathrm{~B} / 0$ cells, these results show that the variants selected for increased FcRn binding exhibit different binding patterns to the complement C1q and the FcyRs.

\section{DISCUSSION}

Due to the remarkable role of FcRn in IgG serum persistence, the $\mathrm{Fc} / \mathrm{FcRn}$ interactions have been comprehensively studied at the molecular level by mutagenesis $(13,53)$ and crystallography (59) using mice, rat, and human FcRn. The FcRn-binding site is highly conserved among species and comprises residues located at the $\mathrm{CH} 2 / \mathrm{CH} 3$ domains interface: residues 252-254, 307, and 309-311 in the $\mathrm{CH} 2$ domain, and residues $433-436$ in the $\mathrm{CH} 3$ domain. Moreover, for the human Fc/FcRn interaction, the $\mathrm{pH}$ dependence has been attributed to the histidine residues $\mathrm{H} 310$ and $\mathrm{H} 435$, involved in salt bridges with acidic FcRn residues. Various human Fc variants with improved FcRn affinity, and conserved $\mathrm{pH}$ dependence, were designed using this structural knowledge and resulted in increased serum half-life. For instance, residues 250 and 428 , which are close to the $\mathrm{CH} 2 / \mathrm{CH} 3$ interface, were targeted by mutagenesis permitting the isolation of the double variant T250Q/M428L (Fc-QL), exhibiting a $~ 27$-fold binding improvement on human FcRn expressed on the cell surface $(16,17)$. In silico analysis was also used to design several variants combining mutations in or close to the FcRn-binding site. Two of these variants, M428L/N434S (IgG-LS, Xtend) and V259I/V308F/M428L (IgGIFL), showed a $\sim 11$ - and $\sim 20$-fold improved binding to human FcRn by SPR, respectively, resulting in approximately four- to fivefold half-life extension in cynomolgus monkeys and threefold half-life extension in hFcRn-transgenic mice (18). On the other hand, the triple variant M252Y/S254T/T256E (IgG-YTE) was obtained by phage display selection against murine FcRn of rationally designed libraries targeting Fc residues in or close to the FcRn-binding site (residues 251-256, 308-314, 385-389, and 428436) (15). When introduced in an anti-RSV and an anti-IL6 IgG1, these YTE mutations increased the IgG binding to human FcRn by about 10 -fold by SPR, resulting in a nearly fourfold increase in serum half-life in cynomolgus monkeys $(23,60)$. Importantly, the anti-RSV YTE variant (motavizumab) resulted in up to fourfold longer half-life in healthy humans, confirming for the first time in humans the concept of half-life extension using Fc-engineered antibodies (26). Interestingly, when the crystal structure of the Fc-YTE mutant (residues 236-444) was compared to its WT counterpart, very few structural changes were observed. Therefore, the greatly enhanced interaction between Fc-YTE and human FcRn is likely mediated by local effects at the substitutions sites $(61,62)$.

Without using this structural knowledge of Fc/FcRn interaction, we previously identified several mutations in the Fc region, which increase FcRn-binding capacity using a fully random mutagenesis approach combined with a $\mathrm{pH}$-dependent selection process by phage display (41). The use of two successive rounds of random mutagenesis and selection directly allowed finding optimized variants, partly because of synergistic effects of the different mutations. The effect of several of these mutations was unpredictable by rational design as the mutated positions were located distantly from the FcRn-binding site, for example, P228 and P230 in the hinge domain and F241, V264, and A330 in the $\mathrm{CH} 2$ domain, and have not been previously described. Nevertheless, the best variants isolated included at least one mutation in the FcRn-binding site (mostly N434S or N434Y). In this study, we used data obtained from random mutagenesis, and from new variants constructed by directed mutagenesis, to verify whether each mutation included in our best variants has indeed a positive effect on the FcRn-binding capacity. Indeed, a minor disadvantage of random mutagenesis is that dispensable mutations could be simultaneously selected and need to be identified afterwards. For one variant only (C6A-78), we identified one mutation that had no effect on FcRn binding (N383S). This result indicates that dispensable mutations are infrequently selected using our system, most of the selected mutations being important for FcRn-binding improvement. Besides, because three single mutations with the greatest FcRn binding were unexpectedly located in the hinge domain (P228L, P228R, and P230S), we cumulated them with our best variants in an attempt to further increase FcRn binding. Surprisingly, additive or neutral effects were observed depending on the parental variant these mutations were added to. These results suggest that designing optimized variants by directed mutagenesis is not straightforward as unpredictable results can be obtained when combining several positive mutations. However, several such rationally designed variants showed further increased FcRn binding by phage-ELISA. When two of these variants were produced as full IgG molecules, C6A-78B (C6A-78/P228L) and C6A-78D (C6A-78/P288R), only the first molecule displayed a modest affinity increase by SPR. This discrepancy could be due to the use of different techniques to measure FcRn-binding. SPR on purified IgG molecules is certainly the most accurate technique but could be less discriminant than the phage-ELISA technique. FcRnbinding improvement up to 28 -fold was obtained by phage-ELISA whereas by SPR the best variant showed a 7.4-fold binding increase (41). Alternatively, the discrepancy observed could arise from the phage display system itself. In this system, the Fc fragment is fused to the N-terminal part of the M13 bacteriophage pIII coat protein. Hence, the N-terminal part of the Fc fragment (226-447) is exposed at the phage surface. The position P228 could be less constrained than in the IgG molecule, favoring the replacement by the arginine, while the substitution by the leucine could conserve a positive impact in both systems.

Despite the potential limitations of the phage display system, we and others have clearly shown the advantages of using this system for the selection of engineered Fcs with modulated binding to FcRn (15). In this system, the Fc fragment is aglycosylated but the $\mathrm{Fc} / \mathrm{FcRn}$ interaction is not dependent on the Fc glycosylation site occupancy (2). Most importantly, the use of the phage display system enables the use of an in vitro selection procedure based on the $\mathrm{pH}$ dependency of the Fc/FcRn interaction, a specific feature that 
is critical to preserve. Indeed, increased affinity at high $\mathrm{pH}$ could be problematic by preventing the release of FcRn-bound IgGs. Augmented clearance was consequently observed for IgG engineered for improved FcRn affinity at both $\mathrm{pH} 6.0$ and $\mathrm{pH} 7.4$, where $\mathrm{pH}$ dependence is reduced (63). Furthermore, recent studies emphasized the difficulty of conserving the $\mathrm{pH}$ dependency because when a variant's affinity to FcRn is increased at $\mathrm{pH} 6.0$, its binding at higher $\mathrm{pH}$ increases accordingly $(21,64)$. Several mutations demonstrating a slight increase in FcRn binding at $\mathrm{pH} 7.4$ were described, among which M252Y and N434Y. Yet, these mutations are included in variants with increased serum half-life (IgG-YTE and our Fc variants, respectively), suggesting that combinations of several mutations could result in different $\mathrm{pH}$ dependency or that this parameter is not sufficient to predict half-life modulation. Owing to the difficultly of assessing and interpreting the $\mathrm{pH}$ dependence, IgG variants with increased FcRn binding are usually assayed for half-life extension in cynomolgus monkeys and/or in hFcRn mice. These FcRn-humanized mice, unlike wild-type mice, have been shown to be a reliable surrogate for studying human IgG serum half-life $(20,65,66)$. Indeed, human and murine FcRn have significant molecular differences, especially concerning $\mathrm{pH}$ dependency, rendering wild-type mice an inadequate model for studying half-life of engineered human IgGs (67-70). In these hFcRn mice, several Fc-engineered variants showed equivalent half-life increase ( 3-fold), despite distinct affinity improvements, suggesting that Fc engineering may have reached a plateau for FcRn improvement designed to increase half-life $(18,20)$. Likewise, our best Fc variants administered to $\mathrm{hFcRn}$ showed extended half-life, ranging from 1.8- to 2.8-fold increase (41). Most of the variants described herein were not tested in hFcRn mice and we cannot predict their behavior in vivo.

A great advantage of the fully random mutagenesis approach used is that identified mutations are distributed all over the length of the Fc region, potentially having an impact on all effector functions. We indeed showed that these FcRn optimized Fc variants display diverse binding capacities to the complement $\mathrm{Clq}$ and the Fc $\gamma$ Rs, resulting in modulated effector activities with increased, conserved, or decreased ADCC and/or CDC activities. Because these activities are essential for the therapeutic efficacy of mAbs, our studies were not limited to one but several Fc variants, which were stored and documented in a database, providing us with distinct "fit-for-purpose" Fc molecules. This database now includes more than 1500 molecules with diverse binding properties. The optimal Fc properties of a given therapeutic mAb are adjustable and will depend on the antibody mode of action (agonistic, cytotoxic, blocking. ..), and on the antigen and pathology targeted. MAbs can trigger a variety of effects by engaging the complement $\mathrm{Clq}$ and different Fc $\gamma$ Rs expressed by immune cells thus the adequate binding profile for a given molecule needs to be defined. Besides, ADCC activity has been clearly associated with the therapeutic efficacy of mAbs in oncology, but many questions remain concerning the respective roles of ADCC, CDC, and ADCP activities. For other therapeutic applications, like for instance, for anti-viral antibodies, the importance of Fc-dependent effector functions was established for mAbs against several infectious pathogens including HIV (71), RSV (72), and Ebola virus (73). Therefore, many protein-Fc-engineered $\mathrm{mAbs}$ with increased

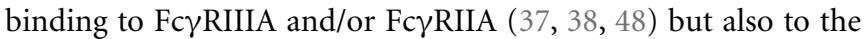
complement C1q $(47,74)$ have been designed in an attempt to enhance therapeutic efficacy and several such engineered $m A b s$ are now in clinical trials $(75,76)$. Besides, glyco-engineered $\mathrm{mAbs}$ with enhanced ADCC due to low or afucosylation are now used clinically (40). We previously showed that such a glyco-engineering technology, LFB's EMABling ${ }^{\circledR}$ platform, can be combined with protein-Fc engineering to increase half-life (41). Indeed, when produced in YB2/0 cells, permitting low-fucose content in the Fc glycan moiety, most of our IgG variants conserved improved ADCC, in correlation with Fc $\gamma$ RIIIA binding. In contrast, when produced in HEK293 cells, a cell line classically resulting in high fucose content, Fc $\gamma$ RIIIA binding results were significantly different from the ADCC results previously obtained. These results suggest that glyco- and Fc-protein engineering can elicit noncompatible effects, resulting in different ADCC activities depending on the production cell line. This divergence between cell lines was not observed when CDC activities and complement C1q binding were compared. This was expected as fucosylation, which is known to have no influence on this effector property.

Finally, the C6A-66 variant showed poor binding to the complement C1q and all Fc $\gamma$ Rs as well as loss of ADCC and CDC activities. These characteristics are probably due to an unusual deletion of one amino acid, located in position 294. Nonetheless, this variant could be of great interest as for certain clinical applications no effector function could be preferable and, for this variant, $\mathrm{ADCC}$ and $\mathrm{CDC}$ are completely abolished while half-life is largely enhanced (77). For example, many anti-cytokine mAbs are currently developed as IgG4 or IgG2 mAbs because they display lower effector functions $(1,78,79)$, such mAbs could be developed with our C6A-66 variant. The IgG-YTE positive control showed similarly reduced effector activities and decreased binding to the complement $\mathrm{Clq}$ and to all Fc $\gamma$ Rs. The reduced ADCC activity of this variant has been observed before and was restored by addition of mutations S239D/A330L/I332E, known to strongly enhance Fc $\gamma$ RIIIA binding (60). We show here that producing the IgG-YTE variant as a low fucosylated molecule cannot restore ADCC activity. Overall, the results obtained for the YTE variant are surprising since this variant comprises three mutations M252Y/S254T/T256E located exclusively in the FcRn-binding site, as clearly observed by crystallography (61). It is noteworthy that $\mathrm{Clq}$ and the $\mathrm{Fc} \gamma \mathrm{Rs}$ bind to a region involving the hinge and the hinge-proximal portion of the $\mathrm{CH} 2$ domain. This region is distant from the $\mathrm{CH} 2 / \mathrm{CH} 3$ domain interface containing the residues implicated in FcRn binding. Since mutations at the FcRn-binding site seem to have a great impact on Fc $\gamma$ Rs and C1q binding as well, these binding sites cannot be considered as independent just because of their relative distant localization. We therefore provide evidence that half-life and effector functions should be optimized simultaneously. Comprehensive understanding of these interactions will not only allow for development of effective therapeutics but also avoidance of potential adverse effects.

\section{ACKNOWLEDGMENTS}

Our sincere thanks to Alain Longue, Anne-Sophie Dezetter, Aurélie Dehenne, Virginie Beghin, Cécile Beghin, and Aurélie Terrier for antibody production and characterization, Véronique Devos for 
SPR analyses, Gilles Dupont for ADCC and CDC assays, Ouafa Zaki and Nathalie Souyris for phage display constructions, Fabien Crozet and Thomas Raulet for bioinformatics. This work was supported by a French governmental grant (FUI 10, HuMabFc project) financed by DGCIS and Oséo.

\section{SUPPLEMENTARY MATERIAL}

The Supplementary Material for this article can be found online at http://www.frontiersin.org/Journal/10.3389/fimmu.2015.00039/ abstract

\section{REFERENCES}

1. Reichert JM. Antibodies to watch in 2014: mid-year update. MAbs (2014) 6:799-802. doi:10.4161/mabs.29282

2. Ward ES, Ober RJ. Chapter 4: multitasking by exploitation of intracellular transport functions the many faces of FcRn. Adv Immunol (2009) 103:77-115. doi:10.1016/S0065-2776(09)03004-1

3. Kuo TT, Baker K, Yoshida M, Qiao SW, Aveson VG, Lencer WI, et al. Neonatal Fc receptor: from immunity to therapeutics. J Clin Immunol (2010) 30:777-89. doi:10.1007/s10875-010-9468-4

4. Bitonti AJ, Dumont JA, Low SC, Peters RT, Kropp KE, Palombella VJ, et al. Pulmonary delivery of an erythropoietin Fc fusion protein in non-human primates through an immunoglobulin transport pathway. Proc Natl Acad Sci U S A (2004) 101:9763-8. doi:10.1073/pnas.0403235101

5. Ye L, Zeng R, Bai Y, Roopenian DC, Zhu X. Efficient mucosal vaccination mediated by the neonatal Fc receptor. Nat Biotechnol (2011) 29:158-63. doi:10.1038/nbt.1742

6. Pridgen EM, Alexis F, Kuo TT, Levy-Nissenbaum E, Karnik R, Blumberg RS, et al. Transepithelial transport of Fc-targeted nanoparticles by the neonatal fc receptor for oral delivery. Sci Transl Med (2013) 5:213ra167. doi:10.1126/scitranslmed. 3007049

7. Qiao SW, Kobayashi K, Johansen FE, Sollid LM, Andersen JT, Milford E, et al. Dependence of antibody-mediated presentation of antigen on FcRn. Proc Natl Acad Sci U S A (2008) 105:9337-42. doi:10.1073/pnas.0801717105

8. Baker K, Qiao SW, Kuo TT, Aveson VG, Platzer B, Andersen JT, et al. Neonatal Fc receptor for $\operatorname{IgG}(\mathrm{FcRn})$ regulates cross-presentation of IgG immune complexes by CD8-CD11b+ dendritic cells. Proc Natl Acad Sci U S A (2011) 108:9927-32. doi:10.1073/pnas.1019037108

9. Hoffmann E, Kotsias F, Visentin G, Bruhns P, Savina A, Amigorena S. Autonomous phagosomal degradation and antigen presentation in dendritic cells. Proc Natl Acad Sci U S A (2012) 109:14556-61. doi:10.1073/pnas. 1203912109

10. Vidarsson G, Stemerding AM, Stapleton NM, Spliethoff SE, Janssen H, Rebers $\mathrm{FE}$, et al. FcRn: an IgG receptor on phagocytes with a novel role in phagocytosis. Blood (2006) 108:3573-9. doi:10.1182/blood-2006-05-024539

11. Rath T, Baker K, Dumont JA, Peters RT, Jiang H, Qiao SW, et al. Fc-fusion proteins and FcRn: structural insights for longer-lasting and more effective therapeutics. Crit Rev Biotechnol (2013). doi:10.3109/07388551.2013.834293

12. Kuo TT, Aveson VG. Neonatal Fc receptor and IgG-based therapeutics. MAbs (2011) 3:422-30. doi:10.4161/mabs.3.5.16983

13. Shields RL, Namenuk AK, Hong K, Meng YG, Rae J, Briggs J, et al. High resolution mapping of the binding site on human IgG1 for Fc gamma RI, Fc gamma RII, Fc gamma RIII, and FcRn and design of IgG1 variants with improved binding to the Fc gamma R. J Biol Chem (2001) 276:6591-604. doi:10.1074/jbc.M009483200

14. Martin WL, West AP Jr, Gan L, Bjorkman PJ. Crystal structure at 2.8 A of an FcRn/heterodimeric Fc complex: mechanism of $\mathrm{pH}$-dependent binding. $\mathrm{Mol}$ Cell (2001) 7:867-77. doi:10.1016/S1097-2765(01)00230-1

15. Dall'acqua WF, Woods RM, Ward ES, Palaszynski SR, Patel NK, Brewah YA, et al. Increasing the affinity of a human IgG1 for the neonatal Fc receptor: biological consequences. J Immunol (2002) 169:5171-80. doi:10.4049/jimmunol.169. 9.5171

16. Hinton PR, Johlfs MG, Xiong JM, Hanestad K, Ong KC, Bullock C, et al. Engineered human IgG antibodies with longer serum half-lives in primates. J Biol Chem (2004) 279:6213-6. doi:10.1074/jbc.C300470200

17. Hinton PR, Xiong JM, Johlfs MG, Tang MT, Keller S, Tsurushita N. An engineered human IgG1 antibody with longer serum half-life. J Immunol (2006) 176:346-56. doi:10.4049/jimmunol.176.1.346
18. Zalevsky J, Chamberlain AK, Horton HM, Karki S, Leung IW, Sproule TJ, et al. Enhanced antibody half-life improves in vivo activity. Nat Biotechnol (2010) 28:157-9. doi:10.1038/nbt.1601

19. Dall'acqua WF, Cook KE, Damschroder MM, Woods RM, Wu H. Modulation of the effector functions of a human IgG1 through engineering of its hinge region. J Immunol (2006) 177:1129-38. doi:10.4049/jimmunol.177.2.1129

20. Petkova SB, Akilesh S, Sproule TJ, Christianson GJ, Al KH, Brown AC, et al. Enhanced half-life of genetically engineered human IgG1 antibodies in a humanized FcRn mouse model: potential application in humorally mediated autoimmune disease. Int Immunol (2006) 18:1759-69. doi:10.1093/intimm/dxl110

21. Yeung YA, Leabman MK, Marvin JS, Qiu J, Adams CW, Lien S, et al. Engineering human IgG1 affinity to human neonatal Fc receptor: impact of affinity improvement on pharmacokinetics in primates. JImmunol (2009) 182:7663-71. doi:10.4049/jimmunol.0804182

22. Yeung YA, Wu X, Reyes AE, Vernes JM, Lien S, Lowe J, et al. A therapeutic anti-VEGF antibody with increased potency independent of pharmacokinetic half-life. Cancer Res (2010) 70:3269-77. doi:10.1158/0008-5472.CAN-09-4580

23. Finch DK, Sleeman MA, Moisan J, Ferraro F, Botterell S, Campbell J, et al. Whole-molecule antibody engineering: generation of a high-affinity anti-IL6 antibody with extended pharmacokinetics. J Mol Biol (2011) 411:791-807. doi:10.1016/j.jmb.2011.06.031

24. Igawa T, Ishii S, Tachibana T, Maeda A, Higuchi Y, Shimaoka S, et al. Antibody recycling by engineered $\mathrm{pH}$-dependent antigen binding improves the duration of antigen neutralization. Nat Biotechnol (2010) 28:1203-7. doi:10.1038/nbt.1691

25. Bernett MJ, Chu SY, Leung I, Moore GL, Lee SH, Pong E, et al. Immune suppression in cynomolgus monkeys by XPro9523: an improved CTLA4-Ig fusion with enhanced binding to CD80, CD86 and neonatal Fc receptor FcRn. MAbs (2013) 5(3):384-96. doi:10.4161/mabs.23976

26. Robbie GJ, Criste R, Dall'acqua WF, Jensen K, Patel NK, Losonsky GA, et al. A novel investigational Fc-modified humanized monoclonal antibody, motavizumab-YTE, has an extended half-life in healthy adults. Antimicrob Agents Chemother (2013) 57:6147-53. doi:10.1128/AAC.01285-13

27. Albanesi M, Daeron M. The interactions of therapeutic antibodies with Fc receptors. Immunol Lett (2012) 143:20-7. doi:10.1016/j.imlet.2012.02.005

28. Gillis C, Gouel-Cheron A, Jonsson F, Bruhns P. Contribution of human FcgammaRs to disease with evidence from human polymorphisms and transgenic animal studies. Front Immunol (2014) 5:254. doi:10.3389/fimmu.2014. 00254

29. Cartron G, Dacheux L, Salles G, Solal-Celigny P, Bardos P, Colombat P, et al. Therapeutic activity of humanized anti-CD20 monoclonal antibody and polymorphism in IgG Fc receptor FcgammaRIIIa gene. Blood (2002) 99:754-8. doi:10.1182/blood.V99.3.754

30. Cooper N, Stasi R, Cunningham-Rundles S, Cesarman E, McFarland JG, Bussel JB. Platelet-associated antibodies, cellular immunity and FCGR3a genotype influence the response to rituximab in immune thrombocytopenia. Br J Haematol (2012) 158:539-47. doi:10.1111/j.1365-2141.2012.09184.x

31. Ruyssen-Witrand A, Rouanet S, Combe B, Dougados M, Le Loët X, Sibilia J, et al. Fcgamma receptor type IIIA polymorphism influences treatment outcomes in patients with rheumatoid arthritis treated with rituximab. Ann Rheum Dis (2012) 71:875-7. doi:10.1136/annrheumdis-2011-200337

32. Musolino A, Naldi N, Bortesi B, Pezzuolo D, Capelletti M, Missale G, et al. Immunoglobulin $G$ fragment $C$ receptor polymorphisms and clinical efficacy of trastuzumab-based therapy in patients with HER-2/neu-positive metastatic breast cancer. J Clin Oncol (2008) 26:1789-96. doi:10.1200/JCO.2007.14.8957

33. Bibeau F, Lopez-Crapez E, Di FF, Thezenas S, Ychou M, Blanchard F, et al. Impact of Fc\{gamma\}RIIa-Fc\{gamma\}RIIIa polymorphisms and KRAS mutations on the clinical outcome of patients with metastatic colorectal cancer treated with cetuximab plus irinotecan. J Clin Oncol (2009) 27:1122-9. doi:10.1200/JCO.2008.18.0463

34. Moroi R, Endo K, Kinouchi Y, Shiga H, Kakuta Y, Kuroha M, et al. FCGR3A158 polymorphism influences the biological response to infliximab in Crohn's disease through affecting the ADCC activity. Immunogenetics (2013) 65:265-71. doi:10.1007/s00251-013-0679-8

35. Strohl WR. Optimization of Fc-mediated effector functions of monoclonal antibodies. Curr Opin Biotechnol (2009) 20:685-91. doi:10.1016/j.copbio.2009. 10.011

36. Lu Y, Vernes JM, Chiang N, Ou Q, Ding J, Adams C, et al. Identification of IgG(1) variants with increased affinity to FcgammaRIIIa and unaltered affinity to FcgammaRI and FcRn: comparison of soluble receptor-based and cell-based 
binding assays. J Immunol Methods (2011) 365:132-41. doi:10.1016/j.jim.2010. 12.014

37. Stavenhagen JB, Gorlatov S, Tuaillon N, Rankin CT, Li H, Burke S, et al. Fc optimization of therapeutic antibodies enhances their ability to kill tumor cells in vitro and controls tumor expansion in vivo via low-affinity activating Fcgamma receptors. Cancer Res (2007) 67:8882-90. doi:10.1158/0008-5472. CAN-07-0696

38. Lazar GA, Dang W, Karki S, Vafa O, Peng JS, Hyun L, et al. Engineered antibody Fc variants with enhanced effector function. Proc Natl Acad Sci U S A (2006) 103:4005-10. doi:10.1073/pnas.0508123103

39. Shields RL, Lai J, Keck R, O'Connell LY, Hong K, Meng YG, et al. Lack of fucose on human IgG1 N-linked oligosaccharide improves binding to human Fcgamma RIII and antibody-dependent cellular toxicity. J Biol Chem (2002) 277:26733-40. doi:10.1074/jbc.M202069200

40. Beck A, Reichert JM. Marketing approval of mogamulizumab: a triumph for glyco-engineering. MAbs (2012) 4:419-25. doi:10.4161/mabs.20996

41. Monnet C, Jorieux S, Souyris N, Zaki O, Jacquet A, Fournier N, et al. Combined glyco- and protein-Fc engineering simultaneously enhance cytotoxicity and half-life of a therapeutic antibody. MAbs (2014) 6:422-36. doi:10.4161/ mabs. 27854

42. Popov S, Hubbard JG, Kim J, Ober B, Ghetie V, Ward ES. The stoichiometry and affinity of the interaction of murine $\mathrm{Fc}$ fragments with the MHC class I-related receptor, FcRn. Mol Immunol (1996) 33:521-30. doi:10.1016/01615890(96)00004-1

43. Kabat EA, Wu TT. Identical V region amino acid sequences and segments of sequences in antibodies of different specificities. Relative contributions of $\mathrm{VH}$ and VL genes, minigenes, and complementarity-determining regions to binding of antibody-combining sites. J Immunol (1991) 147:1709-19.

44. Smith GP. Filamentous fusion phage: novel expression vectors that display cloned antigens on the virion surface. Science (1985) 228:1315-7. doi:10.1126/ science. 4001944

45. Behrens CK, Jorieux S, Kharrat A, Bouayadi K, Mondon P, Monnet-Mars C. Optimized Fc Variants. WO/2010/106180 (2010).

46. Fontayne A, Jorieux S, Monnet-Mars C, Mondon P, Kharrat A, Bouayadi K. Fc Variants with Reduced Effector Functions. WO2012175751 (2012).

47. Idusogie EE, Wong PY, Presta LG, Gazzano-Santoro H, Totpal K, Ultsch M, et al. Engineered antibodies with increased activity to recruit complement. JImmunol (2001) 166:2571-5. doi:10.4049/jimmunol.166.4.2571

48. Richards JO, Karki S, Lazar GA, Chen H, Dang W, Desjarlais JR. Optimization of antibody binding to FcgammaRIIa enhances macrophage phagocytosis of tumor cells. Mol Cancer Ther (2008) 7:2517-27. doi:10.1158/1535-7163.MCT-08-0201

49. Chu SY, Vostiar I, Karki S, Moore GL, Lazar GA, Pong E, et al. Inhibition of B cell receptor-mediated activation of primary human $B$ cells by coengagement of CD19 and FcgammaRIIb with Fc-engineered antibodies. Mol Immunol (2008) 45:3926-33. doi:10.1016/j.molimm.2008.06.027

50. Polyak MJ, Deans JP. Alanine-170 and proline-172 are critical determinants for extracellular CD20 epitopes; heterogeneity in the fine specificity of CD20 monoclonal antibodies is defined by additional requirements imposed by both amino acid sequence and quaternary structure. Blood (2002) 99:3256-62. doi:10.1182/blood.V99.9.3256

51. Mondon P, Souyris N, Douchy L, Crozet F, Bouayadi K, Kharrat H. Method for generation of human hyperdiversified antibody fragment library. Biotechnol $J$ (2007) 2:76-82. doi:10.1002/biot.200600205

52. Clark MR. IgG effector mechanisms. Chem Immunol (1997) 65:88-110. doi:10. $1159 / 000319350$

53. Kim JK, Firan M, Radu CG, Kim CH, Ghetie V, Ward ES. Mapping the site on human IgG for binding of the MHC class I-related receptor, FcRn. Eur J Immunol (1999) 29:2819-25. doi:10.1002/(SICI)1521-4141(199909)29: 09<2819::AID-IMMU2819>3.0.CO;2-6

54. de Romeuf C, Dutertre CA, Le Garff-Tavernier M, Fournier N, Gaucher C, Glacet A, et al. Chronic lymphocytic leukaemia cells are efficiently killed by an anti-CD20 monoclonal antibody selected for improved engagement of FcgammaRIIIA/CD16. Br J Haematol (2008) 140:635-43. doi:10.1111/j.1365-2141. 2007.06974.x

55. Le Garff-Tavernier M, Decocq J, de Romeuf C, Parizot C, Dutertre CA, Chapiro E, et al. Analysis of CD16+CD56dim NK cells from CLL patients: evidence supporting a therapeutic strategy with optimized anti-CD20 monoclonal antibodies. Leukemia (2011) 25:101-9. doi:10.1038/leu.2010.240
56. Abdelwahed RB, Donnou S, Ouakrim H, Crozet L, Cosette J, Jacquet A, et al. Preclinical study of ublituximab, a glycoengineered anti-human CD20 antibody, in murine models of primary cerebral and intraocular B-cell lymphomas. Invest Ophthalmol Vis Sci (2013) 54:3657-65. doi:10.1167/iovs.12-10316

57. Siberil S, de Romeuf C, Bihoreau N, Fernandez N, Meterreau JL, Regenman A, et al. Selection of a human anti-RhD monoclonal antibody for therapeutic use: impact of IgG glycosylation on activating and inhibitory Fc gamma R functions. Clin Immunol (2006) 118:170-9. doi:10.1016/j.clim.2005.10.008

58. Beliard R, Waegemans T, Notelet D, Massad L, Dhainaut F, Romeuf C, et al. A human anti-D monoclonal antibody selected for enhanced FcgammaRIII engagement clears $\mathrm{RhD}+$ autologous red cells in human volunteers as efficiently as polyclonal anti-D antibodies. Br J Haematol (2008) 141:109-19. doi:10.1111/j.1365-2141.2008.06985.x

59. Martin WL, Bjorkman PJ. Characterization of the 2:1 complex between the class I MHC-related Fc receptor and its Fc ligand in solution. Biochemistry (1999) 38:12639-47. doi:10.1021/bi9913505

60. Dall'acqua WF, Kiener PA, Wu H. Properties of human IgG1s engineered for enhanced binding to the neonatal Fc receptor (FcRn). J Biol Chem (2006) 281:23514-24. doi:10.1074/jbc.M604292200

61. Oganesyan V, Damschroder MM, Woods RM, Cook KE, Wu H, Dall'acqua WF Structural characterization of a human $\mathrm{Fc}$ fragment engineered for extended serum half-life. Mol Immunol (2009) 46:1750-5. doi:10.1016/j.molimm.2009. 01.026

62. Oganesyan V, Damschroder MM, Cook KE, Li Q, Gao C, Wu H, et al. Structural insights into neonatal Fc receptor-based recycling mechanisms. J Biol Chem (2014) 289(11):7812-24. doi:10.1074/jbc.M113.537563

63. Vaccaro C, Zhou J, Ober RJ, Ward ES. Engineering the Fc region of immunoglobulin G to modulate in vivo antibody levels. Nat Biotechnol (2005) 23:1283-8. doi:10.1038/nbt1143

64. Igawa T, Maeda A, Haraya K, Tachibana T, Iwayanagi Y, Mimoto F, et al. Engineered monoclonal antibody with novel antigen-sweeping activity in vivo. PLoS One (2013) 8:e63236. doi:10.1371/journal.pone.0063236

65. Tam SH, McCarthy SG, Brosnan K, Goldberg KM, Scallon BJ. Correlations between pharmacokinetics of IgG antibodies in primates vs. FcRntransgenic mice reveal a rodent model with predictive capabilities. MAbs (2013) 5(3):397-405. doi:10.4161/mabs.23836

66. Proetzel G, Roopenian DC. Humanized FcRn mouse models for evaluating pharmacokinetics of human IgG antibodies. Methods (2014) 65(1):148-53. doi:10.1016/j.ymeth.2013.07.005

67. Ober RJ, Radu CG, Ghetie V, Ward ES. Differences in promiscuity for antibodyFcRn interactions across species: implications for therapeutic antibodies. Int Immunol (2001) 13:1551-9. doi:10.1093/intimm/13.12.1551

68. Vaccaro C, Bawdon R, Wanjie S, Ober RJ, Ward ES. Divergent activities of an engineered antibody in murine and human systems have implications for therapeutic antibodies. Proc Natl Acad Sci U S A (2006) 103:18709-14. doi:10.1073/pnas.0606304103

69. Deng R, Loyet KM, Lien S, Iyer S, DeForge LE, Theil FP, et al. Pharmacokinetics of humanized monoclonal anti-tumor necrosis factor-\{alpha\} antibody and its neonatal Fc receptor variants in mice and cynomolgus monkeys. Drug Metab Dispos (2010) 38:600-5. doi:10.1124/dmd.109.031310

70. Andersen JT, Daba MB, Berntzen G, Michaelsen TE, Sandlie I. Cross-species binding analyses of mouse and human neonatal Fc receptor show dramatic differences in immunoglobulin G and albumin binding. J Biol Chem (2010) 285:4826-36. doi:10.1074/jbc.M109.081828

71. Hessell AJ, Hangartner L, Hunter M, Havenith CE, Beurskens FJ, Bakker JM, et al. Fc receptor but not complement binding is important in antibody protection against HIV. Nature (2007) 449:101-4. doi:10.1038/nature06106

72. Hiatt A, Bohorova N, Bohorov O, Goodman C, Kim D, Pauly MH, et al. Glycan variants of a respiratory syncytial virus antibody with enhanced effector function and in vivo efficacy. Proc Natl Acad Sci U S A (2014) 111:5992-7. doi:10.1073/pnas.1402458111

73. Zeitlin L, Pettitt J, Scully C, Bohorova N, Kim D, Pauly M, et al. Enhanced potency of a fucose-free monoclonal antibody being developed as an Ebola virus immunoprotectant. Proc Natl Acad Sci U S A (2011) 108:20690-4. doi:10.1073/pnas.1108360108

74. Moore GL, Chen H, Karki S, Lazar GA. Engineered Fc variant antibodies with enhanced ability to recruit complement and mediate effector functions. MAbs (2010) 2:181-9. doi:10.4161/mabs.2.2.11158 
75. Horton HM, Bernett MJ, Pong E, Peipp M, Karki S, Chu SY, et al. Potent in vitro and in vivo activity of an Fc-engineered anti-CD19 monoclonal antibody against lymphoma and leukemia. Cancer Res (2008) 68:8049-57. doi:10.1158/0008-5472.CAN-08-2268

76. Loo D, Alderson RF, Chen FZ, Huang L, Zhang W, Gorlatov S, et al. Development of an Fc-enhanced anti-B7-H3 monoclonal antibody with potent antitumor activity. Clin Cancer Res (2012) 18:3834-45. doi:10.1158/1078-0432.CCR-120715

77. Labrijn AF, Aalberse RC, Schuurman J. When binding is enough: nonactivating antibody formats. Curr Opin Immunol (2008) 20:479-85. doi:10.1016/j.coi. 2008.05.010

78. Reichert JM. Antibodies to watch in 2014. MAbs (2013) 6(1):5-14. doi:10.4161/ mabs. 27333

79. Chan AC, Carter PJ. Therapeutic antibodies for autoimmunity and inflammation. Nat Rev Immunol (2010) 10:301-16. doi:10.1038/nri2761

Conflict of Interest Statement: Céline Monnet, Sylvie Jorieux, Nathalie Fournier, Christophe De Romeuf, Rémi Urbain, Christian K. Behrens, Philippe Mondon, and Alexandre Fontayne are employees of LFB Biotechnologies and Khalil Bouayadi was employee of MilleGen, both companies financially supported the study. Results of this study are described in patents WO2010106180 and WO2012175751.

Received: 09 September 2014; accepted: 21 January 2015; published online: 04 February 2015.

Citation: Monnet C, Jorieux S, Urbain R, Fournier N, Bouayadi K, De Romeuf C, Behrens CK, Fontayne A and Mondon P (2015) Selection of IgG variants with increased $F c R n$ binding using random and directed mutagenesis: impact on effector functions. Front. Immunol. 6:39. doi: 10.3389/fimmu.2015.00039

This article was submitted to Immunotherapies and Vaccines, a section of the journal Frontiers in Immunology.

Copyright (c) 2015 Monnet, Jorieux, Urbain, Fournier, Bouayadi, De Romeuf, Behrens, Fontayne and Mondon. This is an open-access article distributed under the terms of the Creative Commons Attribution License (CC BY). The use, distribution or reproduction in other forums is permitted, provided the original author(s) or licensor are credited and that the original publication in this journal is cited, in accordance with accepted academic practice. No use, distribution or reproduction is permitted which does not comply with these terms. 